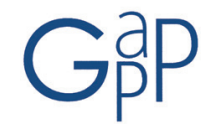

GESTIÓN Y ANÁLISIS DE POLÍTICAS PÚBLICAS, Nueva Época, nº 9 enero-junio 2013 ISSN: 1989-8991

DOI: http://dx.doi.org/10.24965/gapp.voig.10083

\title{
Más allá de la limitaciones económicas y legales de la dependencia: caso de Castilla y León ${ }^{1}$
}

\author{
María Cristina Fernández Ramos \\ Universidad del País Vasco (UPVIEHU) \\ mcrisferra@gmail.com
}

J. Iñaki De La Peña Esteban

Universidad del País Vasco (UPVIEHU) jinaki.delapena@ehu.es

Recibido: 23 de noviembre de 2012

Aceptado: 30 de julio de 2013

\begin{abstract}
Resumen
La falta de autonomía es una situación que se presenta con mayor frecuencia dentro del colectivo de personas mayores. Para paliarlo en España se encuentra vigente la Ley de Dependencia, donde se confiere un grado de gestión de prestaciones al sector privado y a las Comunidades Autónomas. Entre ellas, Castilla y León debido a su población tan envejecida debiera ser uno de los territorios más interesados en desarrollar la normativa relativa a la dependencia.

Por otra parte, el momento económico actual ha dado como resultado fuertes recortes del gasto público. En particular, el capítulo de Atención a la Dependencia ha sido especialmente afectado. Además, el incremento en los precios de los servicios que se prestan en este ámbito, lleva a considerar que las ayudas públicas no son suficientes. Por ello, se deberían estudiar opciones que las complementen.

El desarrollo normativo de la dependencia otorga un derecho subjetivo de carácter universal a los individuos y otorga a las empresas, la seguridad jurídica necesaria para poder operar en los mercados. Del estudio del marco normativo tanto a nivel estatal como a nivel regional, se puede concluir que es factible desarrollar productos financieros y actuariales que limen las diferencias entre los territorios de las comunidades autónomas.
\end{abstract}

\section{Palabras clave}

Envejecimiento de la población; Dependencia; Productos Financieros.

\section{Overcoming Economic and Legal Limitations of Dependency: case of Castilla and León}

Abstract

The lack of independence is a frequent problem faced by the elderly population. In order to combat this situation, the Spanish Dependent Persons' Law decrees that benefits for elderly people be managed by the private sector and/or local government. Among the Spanish regions, Castilla and León being a region with one of the highest number of elderly citizens in the Spanish state, has a vested interest in providing adequate coverage for the elderly.

The current economic climate has led to severe cuts in public spending. Spending on Dependent Persons' benefits has been particularly affected. As the result of a concurrent increase in the cost of those services contracted in this area, the public funds available are no longer sufficient to meet demand. Consequently, it is a matter of need that a study of complementary options is undertaken.

The Dependent Persons' Law grants a universal right of benefits to citizens whilst also providing the necessary framework for the provision of private services in order to satisfy this universal right. This paper suggests that in accordance with central government and regional government laws, the development and application of financial and actuarial products might ameliorate the differences in coverage between the different Spanish regions.

\section{Keywords}

Aging population, Dependency, Financial Products.

1 Trabajo realizado en el marco de UFI 11/51 Dirección Empresarial y Gobernanza Territorial y Social de la UPV/EHU. 


\section{INTRODUCCIÓN}

El envejecimiento de la población es reflejo de avances médicos, mejoras en los métodos de prevención, el fomento de conductas saludables, y tasas de fecundidad bajas, entre otras causas. A nivel mundial, el número de personas mayores de 65 años se triplicó en la segunda mitad del siglo XX hasta llegar a los 417 millones y para el 2050 se espera alcance 1,5 billones. Representaría el 16\% de toda la población mundial. Una de las razones más importantes de ello es la reducción de las tasas de fecundidad y de mortalidad que juegan un papel fundamental en el incremento de la población de edad avanzada tanto en países ricos como pobres (Martin, 2011:34). Como consecuencia se produce un incremento del número de mayores que puede provocar problemas como: financiación de las pensiones (Polo y Viejo, 2011:83) e incremento de costes por cuidados de larga duración (Zanón et al, 2011:117).

Bajo este panorama la comunidad autónoma de Castilla y León se caracteriza por tener una población envejecida. El 20,89\% de la población castellanoleonesa (I.N.E., 2012) es mayor de 67 años y de ésta, el 40,45\% supera los ochenta años. La tasa de discapacidad crece con la edad y se ha comprobado que a partir de estas edades más de la mitad de los españoles tiene dificultades para realizar las actividades de la vida diaria (Abellán y Ayala, 2012:4). Respecto al resto de población los que están en edad de trabajar representan el 67,27\% del total de la población de la comunidad y de ellos más de $57 \%$ son mayores de 40 años. Desde finales del siglo pasado se observa que la proporción de jóvenes se reduce respecto de los de mayor edad (Gómez et al, 2007:5); (Gómez et al, 2011:105). En base a estos datos el desarrollo normativo de la ayuda para la situación de Dependencia debería ser urgente y prioritario.

El objetivo del presente trabajo es la búsqueda de coberturas alternativas que permitan la financiación de las prestaciones de dependencia, que si bien no sustituirán a las públicas, sí podrían ser buenos complementos. Para ello se tendrá en cuenta la normativa existente al efecto, tanto estatal como la autonómica y que es objeto de estudio específico en este trabajo. En todo momento se buscan oportunidades de negocio para el sector privado. Igualmente se detallarán aquellas cuestiones que dificultan la puesta en marcha de determinados productos, sobre todo los actuariales.

Para ello se introduce en el siguiente epígrafe el protagonismo reciente que tiene en nuestro país la cobertura de la dependencia, analizando su financiación, los diferentes niveles de cobertura y las prestaciones tanto económicas como de servicios que se establecen en la normativa. Tras analizarla se podrá apreciar que no cierra las puertas a que las comunidades autónomas regulen y amplíen la oferta de estas ayudas.

Posteriormente analizamos el instrumento fundamental de medición de la dependencia que proporciona la ley: el baremo. Este instrumento sirve de guía para cuantificar la prevalencia de la dependencia en la sociedad. Se observan las limitaciones que tiene a la hora de trasladarse como probabilidades de dependencia. Éstas son la base técnica inexcusable para la oferta de productos actuariales y financieros destinados a la protección de esta contingencia.

A lo largo de este trabajo se hará referencia tanto a la financiación como a la normativa emanada del legislador de Castilla y León con el objetivo de valorar su especificidad respecto del ámbito general. Se estudiarán sobre todo las incompatibilidades que impone la comunidad autónoma, lo cual puede incrementar las oportunidades de negocio para empresas que se dediquen a la cobertura de la dependencia y que no estén sujetas a un ámbito territorial.

Terminaremos con una serie de conclusiones y comentarios sobre el grado de desarrollo que se ha alcanzado en esta comunidad autónoma y las posibles prestaciones que se podrían llegar a desarrollar, así como las referencias bibliográficas empleadas.

\section{IMPORTANCIA ECONÓMICA DE LA COBERTURA DE DEPENDENCIA}

Desde hace algún tiempo el fenómeno del envejecimiento está siendo estudiado con profundidad debido a las grandes consecuencias que puede producir en la sociedad. Dado que la dependencia está asociada indefectiblemente con cumplir años (Abellán y Ayala, 2012:4), la administración debiera tener como objetivo prioritario el fomento y consolidación del sistema de Dependencia creado a raíz de la ley que la regula y que fue aprobada en 2006. La situación de crisis actual está haciendo que se produzcan recortes sonoros que le ha restado efectividad y ha generado un alto coste social (Barriga, 2012: 2), cuando realmente no se ha puesto en marcha en su totalidad, ya que está establecida una aplicación progresiva y la culminación se realizaría en el año 2014. 


\section{CUADRO 1: FACTORES QUE INFLUYEN EN EL GASTO POR PENSIONES}

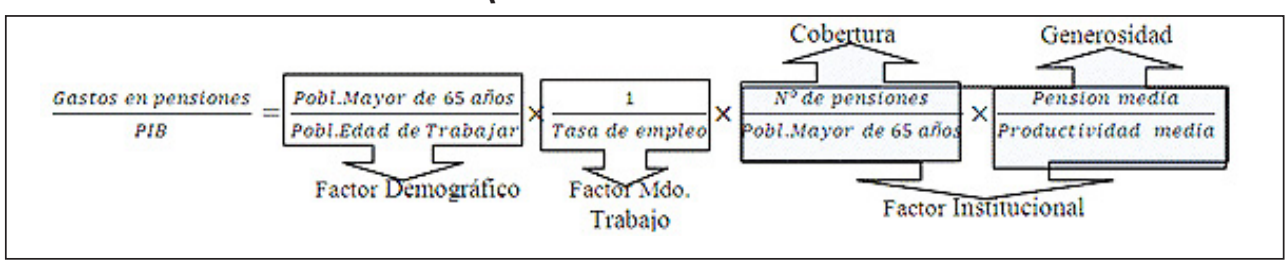

Fuente: Conde-Ruiz y Alonso, 2006: 56.

La mayor población objeto de cobertura (mayor de 67 años) en 10 años se incrementará en casi un 17\% (INE, 201 (b)). Ampliando el horizonte temporal hasta el año 2049, la población en edad de jubilarse representaría alrededor del 30\% (INE, 2010 (a)). Estos datos, indican la presión al alza sobre el gasto público respecto del PIB de las pensiones, lo cual lleva a cuestionarnos si éstas estarán garantizadas si la coyuntura económica no cambia y si la población activa no aumenta lo suficiente (cuadro 1) al ser dos de los factores que influyen notablemente en la variación de este gasto.

CUADRO 2: PORCENTAJE DEL GASTO SOCIAL SOBRE EL PIB

\begin{tabular}{|c|c|c|c|c|c|}
\hline Year & 1980 & 1990 & 2000 & 2010 & 2012 \\
\hline France & 20,8 & 25,1 & 28,6 & 32,2 & 32,1 \\
\hline Denmark & 24,8 & 25,1 & 26,4 & 30,1 & 30,5 \\
\hline Belgium & 23,5 & 24,9 & 25,3 & 29,5 & 30,0 \\
\hline Finland & 18,1 & 24,1 & 24,2 & 29,4 & 29,0 \\
\hline Austria & 22,4 & 23,8 & 26,6 & 28,8 & 28,3 \\
\hline Sweden & 27,1 & 30,2 & 28,4 & 28,3 & 28,2 \\
\hline Italy & 18,0 & 19,9 & 23,1 & 27,8 & 28,1 \\
\hline Germany & 22,1 & 21,7 & 26,6 & 27,1 & 26,3 \\
\hline Spain & 15,5 & 19,9 & 20,2 & 26,5 & 26,3 \\
\hline Portugal & 9,9 & 12,5 & 18,9 & 25,6 & 25,0 \\
\hline Netherlands & 24,8 & 25,6 & 19,8 & 23,5 & 24,3 \\
\hline United Kingdom & 16,5 & 16,7 & 18,6 & 23,7 & 23,9 \\
\hline Slovenia & .. & - & 21,8 & 23,5 & 23,7 \\
\hline Luxembourg & 20,6 & 19,1 & 20,9 & 23,0 & 23,3 \\
\hline Greece & 10,3 & 16,6 & 19,3 & 23,3 & 23,1 \\
\hline Ireland & 16,5 & 17,3 & 13,4 & 23,7 & 23,1 \\
\hline Norway & 16,9 & 22,3 & 21,3 & 23,0 & 22,1 \\
\hline New Zealand & 17,0 & 21,5 & 19,0 & 21,2 & 22,0 \\
\hline OECD-Total & 15,5 & 17,6 & 18,9 & 22,0 & 21,7 \\
\hline Hungary & .. & .. & 20,7 & 22,6 & 21,1 \\
\hline Czech Republic & .. & 15,3 & 19,1 & 20,8 & 20,6 \\
\hline Poland & .. & 14,9 & 20,5 & 21,8 & 20,4 \\
\hline Switzerland & 13,8 & 13,5 & 17,8 & 20,0 & 20,3 \\
\hline UnitedStates & 13,2 & 13,6 & 14,5 & 19,9 & 19,4 \\
\hline Australia & 10,3 & 13,2 & 17,3 & 17,9 & 18,7 \\
\hline Estonia & .. & .. & 13,9 & 20,1 & 18,4 \\
\hline Canada & 13,7 & 18,1 & 16,5 & 18,6 & 18,2 \\
\hline Slovak Republic & .. & .. & 17,9 & 19,0 & 17,6 \\
\hline Iceland & .. & 13,7 & 15,2 & 18,0 & 16,4 \\
\hline Israel & .. & .. & 17,2 & 16,0 & 15,8 \\
\hline Korea & .. & 2,8 & 4,8 & 9,2 & 9,3 \\
\hline
\end{tabular}

Fuente: OECD Social Expenditure Database (SOCX). 
El porcentaje del gasto público destinado al Estado del Bienestar oscila dependiendo del grado de desarrollo del país. No obstante los porcentajes son elevados (cuadro 2). Los países que pertenecen a la OCDE destinan alrededor del 10 al 15\%, mientras que aquellos considerados en vías de desarrollo únicamente del 5 al 10\%.

Ante el incremento de la población mayor, toda Europa está intensificando sus esfuerzos sobre los servicios sanitarios y sociales, soportando un aumento considerable de los costes (Vaquerizo et al, 2011: 4-7) (Arribas et al, 2009: 19-20). En los países de la Unión Europea el gasto que se destina respecto al PIB para los cuidados de larga duración en cada uno de los países es muy dispar. Mientras que Suecia y Holanda encabezan el ranking de las que más porcentaje destinan, el 3,5\%, los que lo hacen por debajo son Portugal y España con un 0,1\% y 0,7\% respectivamente.

En España para el año 2012, los gastos relacionados con la Autonomía personal y Atención a la Dependencia sufrieron un retroceso respecto del año 2011 en concreto el 6,1\%, a pesar de que la representación del gasto social se incrementó pasando de ser del 59,6\% al 66,4\%, (Ministerio de Hacienda y AAPP, 2012: 220). En este año se eliminaron las transferencias a las comunidades autónomas con lo que se incrementó la presión sobre su déficit (Barriga, 2012: 7).

Del gasto presupuestado para este año 2013 las partidas que se llevan un mayor porcentaje son las destinadas al gasto social: pensiones, viviendas, etc. (Ilustración 1).

\section{ILUSTRACIÓN 1: PROYECTO DE DISTRIBUCIÓN DEL GASTO PRESUPUESTADO, EN PORCENTAJE SOBRE EL TOTAL EXCLUIDA LA DEUDA PÚBLICA PARA EL 2013}

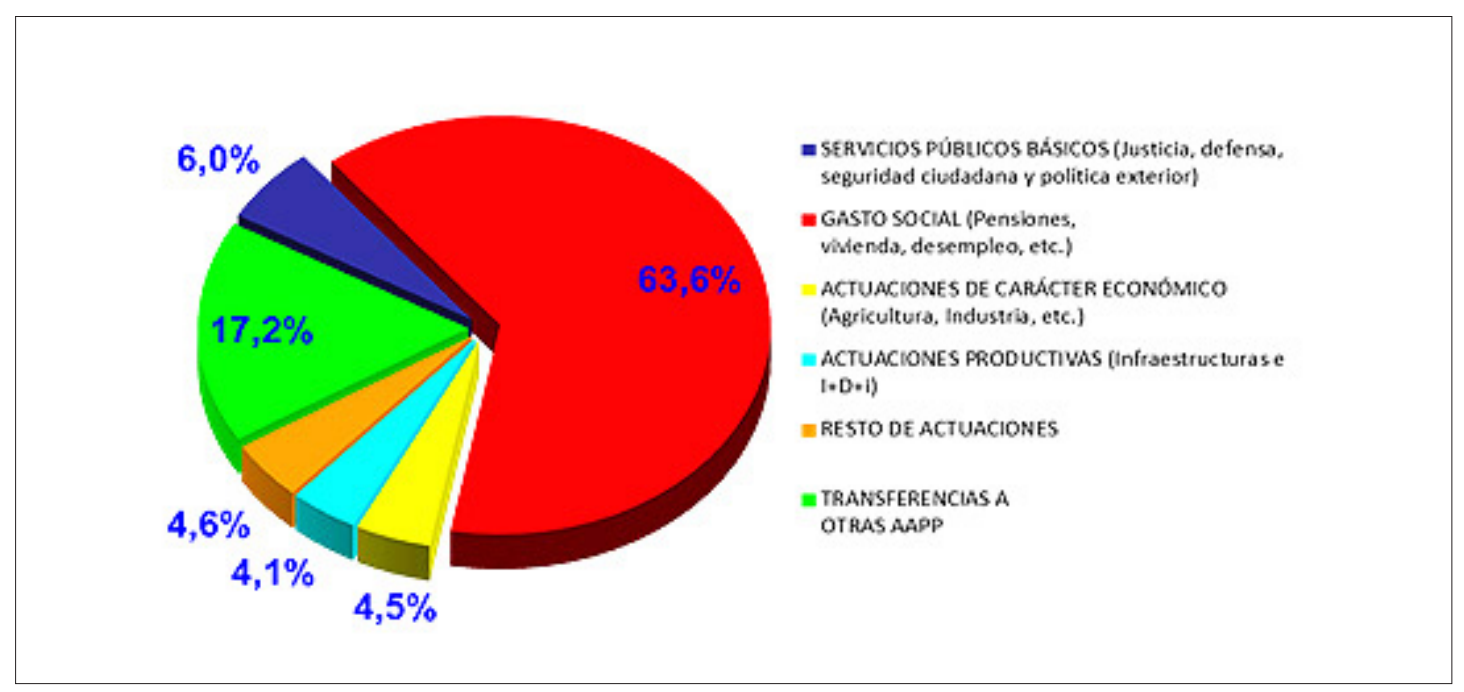

Fuente: La Moncloa, 2012: 13.

Respecto a la atención a la dependencia, el Estado transferirá 2.205,76 millones de euros, de los cuales 1.087,18 millones de euros corresponden a la financiación del mínimo garantizado por el Estado y 1.039,35 millones a las cuotas de los cuidadores no profesionales (PGE, 2013). Las cantidades que se han presupuestado el 2013 parecen más elevadas y representan un mayor porcentaje respecto del año 2012 (Tabla 1). Sin embargo, parte de estas cantidades están destinadas a cumplir con los compromisos adquiridos con las CCAA por el número de personas reconocidas y atendidas en el ejercicio anterior (AEDyGSS, 2013(b))

Desde la puesta en marcha del sistema el peso de la aportación estatal es menor a medida que avanza en su implantación. Se constata que el nivel mínimo garantizado que correría a cargo de los Presupuestos Generales del Estado (PGE) estaría cubriendo como máximo entre un 20\% y 22\% de los costes netos de atención en el momento actual (Barriga, 2012: 6-7).

TABLA 1: PARTICIPACIÓN SObRe El GASTO TOTAL DEL PROGRAMA DE SERVICIOS SOCIALES Y PROMOCIÓN SOCIAL RELATIVA A LA AUTONOMÍA PERSONAL Y ATENCIÓN A LA DEPENDENCIA EN MILES DE UNIDADES MONETARIAS

\begin{tabular}{|c|c|r|c|r|r|r|}
\hline Programa de Gasto 231 I & \multicolumn{1}{c|}{2011} & \% S/ total & \multicolumn{1}{c|}{2012} & $\%$ S/ total & 2013 & $\%$ S/ total \\
\hline Autonomía personal y Att. a la Dependencia & $1.498,44$ & 59,6 & $1.407,15$ & 66,4 & $2.205,76$ & $77,53 \%$ \\
\hline
\end{tabular}

Fuente: Elaboración propia a partir de los presupuestos Generales del Estado de 2013 y el Informe Económico financiero de los presupuestos generales del Estado de 2012. 
En Castilla y León no existe concretamente una partida dedicada a la dependencia, sino que dentro del área de gasto de protección y promoción social hay varios subprogramas que aglutinan en su conjunto la atención a las personas que tienen algún grado de dependencia:

- Atención a las personas con discapacidad.

- Atención a las personas mayores.

- Atención a la infancia.

- Promoción y apoyo a la familia.

Este hecho hace que no se puedan estimar de una manera fiable y directa el gasto que esta Comunidad Autónoma destina a este fin. El observatorio de la dependencia realiza sus cálculos en base a la detracción de los costes totales de atención sobre las aportaciones de la Administración General del Estado (AGE). Como puede observarse en el Gráfico 1, la aportación de las CCAA no hace más que aumentar al igual que la de los usuarios. No obstante el esfuerzo que realizan estos últimos es mayor que el de la administración regional en tasas de crecimiento (Barriga, 2012: 9-12).

Además, a medida que aumenta la población mayor se va generando un problema de coste para la Seguridad Social por las nuevas necesidades que van a ir surgiendo (Adelantado, 2009:82); (Muñoz y Santos, 2012:21). No se trata únicamente de gastos en sanidad primaria (Puga et al, 2011:531-535); (Blanco et al, 2013: 220-221), sino también relacionados con cuestiones geriátricas (Ahn, et al, 2003: 72-73) y avances tecnológicos (Hidalgo, et al., 2010:4-10).

GRÁfico 1: PorcentaJes de FinANCIACIÓn AL SISTEMA DE DEPENDENCIA DE ESPAÑa

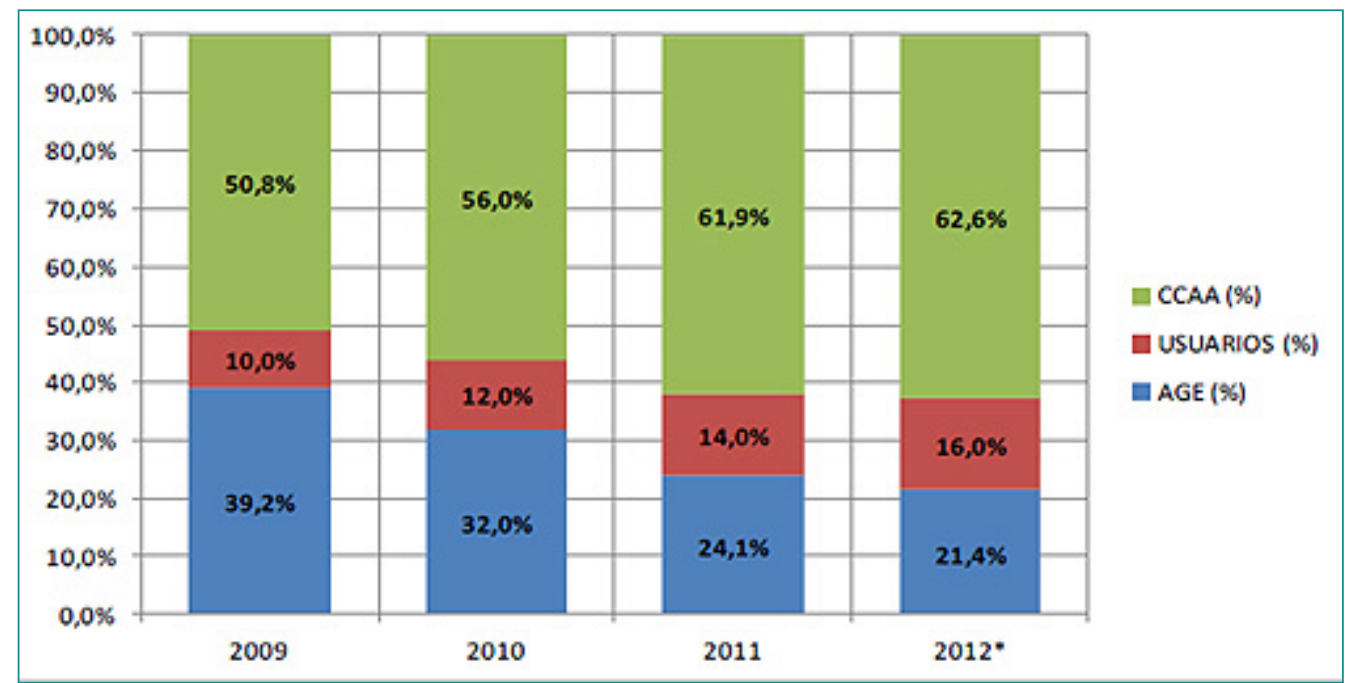

Fuente: Barriga, et al, 2013: 12 .

Castilla y León es junto a Galicia, Extremadura, Principado de Asturias, Cantabria y Andalucía, las comunidades autónomas que tienen mayor coste per cápita de la dependencia, (Alonso et al, 2011:19).

Los últimos estudios realizados por la Junta de Castilla y León reflejan que los ingresos que reciben los mayores castellanoleoneses son los procedentes de la jubilación (Gráfico 2). En la mayoría de los casos representa una prestación escasa y además se le exige un mayor esfuerzo de aportación para la cobertura de dependencia. La situación económica actual hace que muchos de ellos no puedan recibir la atención que realmente precisan por los recortes mencionados. Además hay que hacer hincapié en que las nuevas tecnologías encarecen los precios de la prestación de los servicios a estas personas (Hidalgo et al, 2010: 4-10). Esta situación podría llegar a tratarse como un caso "selección adversa" en la que los que más atención necesitan son los que menos posibilidades tienen de recibirla a consecuencia de sus bajos ingresos. 
GRÁFICO 2: Nivel DE INGRESOS NETOS MENSUALES DE LOS MAYORES CASTELLANO Y LEONESES

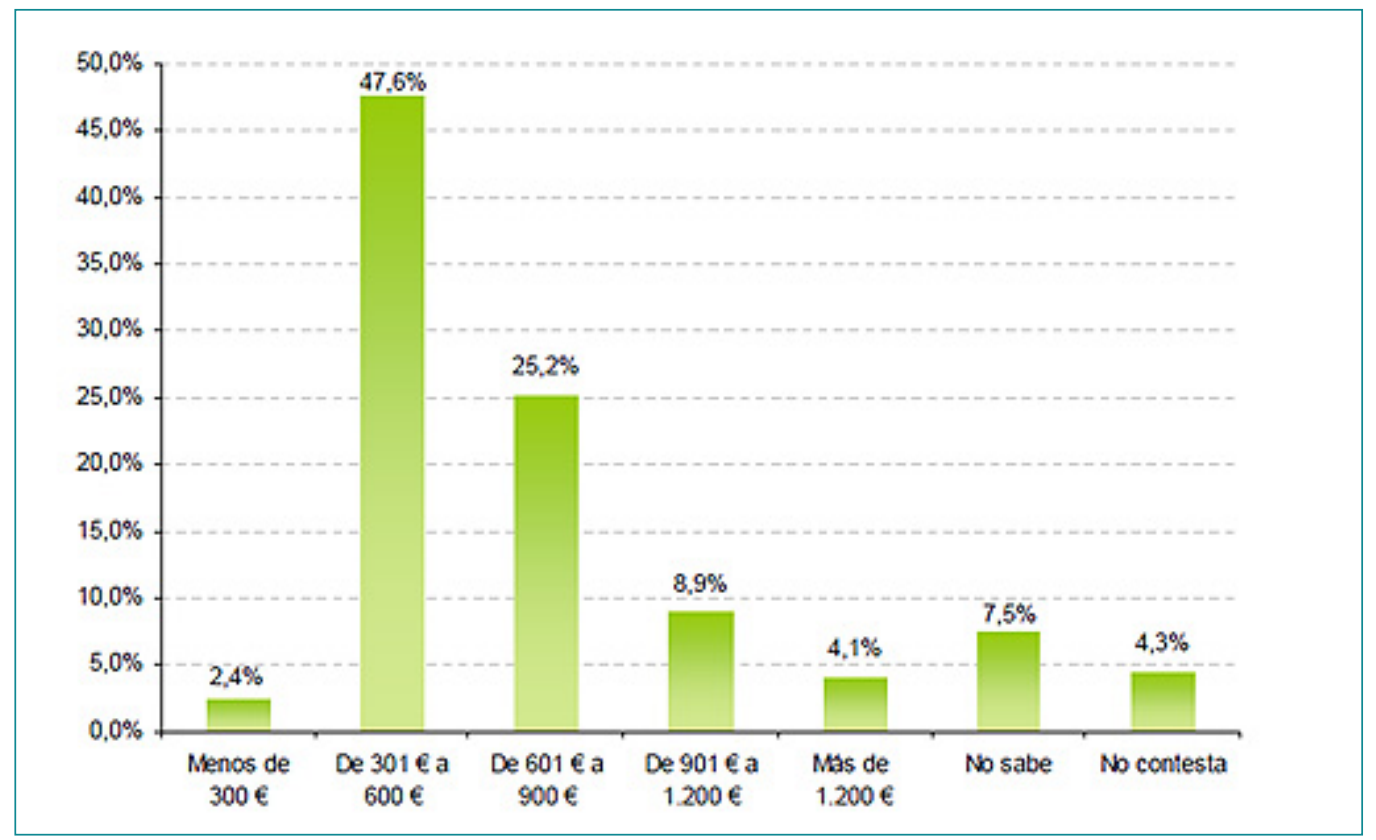

Fuente: Junta de Castilla y León, 2008.

El 50\% de los mayores esta comunidad autónoma no ingresa más de $600 €$ netos mensuales. Sin embargo, la mayor parte de los mayores poseen propiedades (Banco de España, 2010: 41) que pueden licuar a través de ciertos productos financieros. Uno de los más populares sería la hipoteca inversa, si bien no está teniendo gran éxito a pesar de que representan un producto financiero muy útil para este fin. La explicación más obvia al respecto es que las personas mayores desean transmitir sus posesiones en herencia (Sánchez y Quiroga, 2007:74-86). No obstante, no es el único factor que ralentiza el desarrollo del producto. La crisis inmobiliaria actual es otro factor de gran peso por la bajada en los precios de las viviendas (Naredo y Carpintero, 2011: 100-103).

TABLA 2: PORCENTAJE DE HOGARES ESPAÑOLES QUE POSEEN UNA VIVIENDA PRINCIPAL Y OTRAS PROPIEDADES INMOBILIARIAS Y NIVEL DE RENTA MEDIANA EN $€$ (DE LA VIVIENDA)

\begin{tabular}{|c|c|c|c|c|}
\hline \multirow{2}{*}{\multicolumn{2}{|c|}{ Total de los hogares }} & Vivienda principal & $\begin{array}{c}\text { Otras propiedades inmo- } \\
\text { biliarias }\end{array}$ & $\begin{array}{c}\text { Valor mediano de las } \\
\text { viviendas }\end{array}$ \\
\hline & & 82,7 & 36,1 & 180.300 \\
\hline \multirow{6}{*}{ 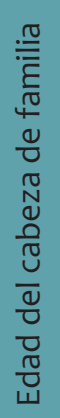 } & Menor de 35 & 65,8 & 18,8 & 178.200 \\
\hline & Entre 35 y 44 años & 78,1 & 29,7 & 180.300 \\
\hline & Entre 45 y 54 años & 86,0 & 41,1 & 180.300 \\
\hline & Entre 55 y 64 años & 89,3 & 51,4 & 204.300 \\
\hline & Entre 65 y 74 años & 88,5 & 45,1 & 180.100 \\
\hline & Mayor de 74 años & 87,8 & 27,1 & 150.300 \\
\hline
\end{tabular}

Fuente: Extraído de la Encuesta Financiera de las Familias (EFF). Banco de España. 2010: 41.

Por otro lado, los costes a los que se pueden llegar a enfrentar un mayor dependiente son en términos generales, superiores a los ingresos mensuales antes apuntados y lo que se pueda obtener por la simple venta de su vivienda. La duración de estos cuidados (cuidados de larga duración -CLD-) no desaparece si no es hasta el fallecimiento.

Hacer frente a estos costes de forma individual con los recortes económicos actuales es impensable. Hay que tener en cuenta que los servicios que se apuntan en la tabla 3 son servicios públicos y que, por lo general, los ser- 
vicios privados tienen un coste más elevado. Así pues, dichas cifras arrojan un límite inferior respecto del coste al que deben hacer frente. En Castilla y León la Resolución de 27 de julio de 2012 establece el coste máximo de plaza ocupada en lo referente a los servicios concertados: lo que se gasta la administración es inferior a lo que supone el mismo servicio en el mercado.

TABLA 3: COSTE DE LOS CUIDADOS DE LARGA DURACIÓN POR HORA O ANUAL EN $€$

\begin{tabular}{|l|r|r|r|}
\hline \multicolumn{1}{|c|}{ Tipos de cuidados de larga duración } & \multicolumn{1}{c|}{1999} & \multicolumn{1}{c|}{2008} & \multicolumn{1}{c|}{ Variación 1999-2008 } \\
\hline Servicios de ayuda a domicilio (por hora) & 8,34 & 12,71 & $52,40 \%$ \\
\hline Servicios públicos de teleasistecia (anual) & 273,53 & 253,92 & $-7,17 \%$ \\
\hline Servicios públicos de día (anual plaza) & $5 \cdot 510,49$ & $7.873,32$ & $42,88 \%$ \\
\hline Plazas residenciales públicas (anual plaza) & $12.870,34$ & $17.295,60$ & $34,38 \%$ \\
\hline
\end{tabular}

Fuente: Extraído de Ayuso y Guillén, 2011.

Se deben articular medidas financieras desde la perspectiva individual privada para que se puedan reducir los efectos de la falta de recursos públicos, bien a través de medidas adecuadas de licuación de patrimonio bien a través de productos que fomenten el ahorro a largo plazo, (Fernández y De la Peña, 2012:498).

La conclusión de este epígrafe es la gran importancia que para la sociedad española en general y para la de Castilla y León en particular tiene la dependencia sobre todo desde el punto de vista económico.

Sin embargo, para llegar a hablar de problemas en la financiación del sistema de pensiones de la Seguridad Social ha sido necesario que transcurriese mucho tiempo. Podríamos partir de los primeros vestigios de protección social en la antigua Roma a través de La Lex Falcida, que puede ser considerada como la primera ley que regulaba el primer plan de previsión público para los legionarios que se retiraban (De La Peña, 2000 (a): 33-34). Pasando por organizaciones creadas en la Edad Media. La Revolución Industrial trajo consigo una mejora de las condiciones de vida de los ciudadanos, que se reflejaron en un aumento de la supervivencia.

No ha sido hasta el siglo XX cuando la prestación por vejez ha empezado a convertirse en una prioridad y en el futuro inmediato se consolidará su importancia. Se intentará que el papel de las prestaciones de servicios sea mayor frente a las económicas. Se puede decir, que la Ley de la Dependencia es la confirmación de este hecho. Aunque algunos autores (Maldonado, 2002: 23 - 24) opinan que la sustitución de prestaciones económicas por prestaciones de servicios no se puede sino valorarse negativamente.

\section{LEY DE DEPENDENCIA}

La Ley 39/2006, de 14 de diciembre, de Promoción de la Autonomía Personal y Atención a las personas en situación de dependencia (LAPAD), recoge por primera vez en nuestro país el derecho subjetivo, individual y universal de los ciudadanos a recibir atención específica cuando sea considerado por los organismos competentes como dependiente, (Pérez y Baeza, 2006: 18-19) (Adelantado, 2009:84).

Para valorar la situación de dependencia se deben cumplimentar una serie de ítems referentes a una serie de actividades y tareas medidas a través de un baremo. El personal encargado de realizarlo lo determina la comunidad autónoma correspondiente. En el caso de Castilla y León deberá suscribir las condiciones de salud el personal sanitario competente si la persona está ya incluida previamente en un servicio de atención domiciliaria o si se trata de pacientes inmovilizados dependientes del Servicio de Atención Primaria del Servicio de Salud. Si es mayor de tres años y no pertenece a los colectivos mencionados, el encargado de realizar la valoración será el trabajador social correspondiente al Centro de Acción Social que corresponda a su domicilio (Orden Fam/73/2012: 12413).

Los grados de severidad en los que se pueden clasificar los dependientes son: Grado I o dependencia moderada; Grado II o dependiente severo y Grado III o gran dependiente. Antes de aprobarse el Real Decreto Ley 20/2012, de 13 de julio de medidas para garantizar la estabilidad presupuestaria y de fomento de la competitividad, estos grados se dividían en dos niveles. Por cada grado y nivel se otorgaban unos importes económicos garantizados por la AGE (Anexo II) y aprobados por Real Decreto. A consecuencia fundamentalmente de la crisis económica actual, se aprobó eliminar los niveles con el fin de reducir el gasto en esta partida (RD-L 20/2012 de 13 de julio: 50435). En Castilla y León desde la aplicación de la LAPAD no ha mejorado las cuantías máximas otorgadas por la AGE, sin embargo, a partir de agosto de 2012 las cuantías que ofrecen son distintas a las fijadas por el estado (Anexo II, tabla 10).

Estos importes garantizados pueden considerarse como una franquicia dentro de un producto financiero lo cual puede llegar a abaratar su coste (Fernández y De la Peña, 2012: 498). 
Con los resultados del baremo (tipo de dependiente y grado de severidad) la AGE diseña un Programa Individual de Atención (PIA). En él se describen cuáles son las prestaciones que recibirá el paciente. En este punto el dependiente se configura como un mero sujeto pasivo de recursos sin poder definir sus propias necesidades y derechos (Pérez y Baeza, 2006:20). Este es un documento que aún hoy no se ha regulado en Castilla y León como tal y esta situación fue muy criticada (PCCyL, 2008:7) por comparación respecto de otras autonomías² que sí lo habían hecho. Se decidió incluirlo en una normativa específica (Resolución de 29 de abril de 2010) en la que se unificaron no sólo el PIA sino también el reconocimiento de la dependencia y la elección de los servicios y prestaciones correspondientes (PCCyL, 2010: 5). Ello supone una ventaja al recortar los plazos de resolución.

El sistema se configura como una red en la que se integran los servicios tanto públicos como privados, en los que colaboran y participan todas las Administraciones Públicas en el ejercicio de sus competencias. Se distribuye en tres niveles: Básico, garantizado por la Administración General del Estado; Complementario, en el que participan conjuntamente las CCAA y la Administración General y Mejora desarrollado por las CCAA y el sector privado.

El cauce de cooperación entre las distintas Administraciones del Estado es el Consejo Territorial del Sistema para la Autonomía y Atención a la Dependencia (CTSAAD). Se encarga de establecer los objetivos, medios y recursos para la aplicación de los servicios y prestaciones a través de convenios, anuales o plurianuales. En estos convenios se fija la financiación que le corresponderá a cada administración de cada CCAA, atendiendo a criterios como población dependiente; dispersión geográfica; insularidad; emigrantes retornados, etc.

Las prestaciones a otorgar pueden ser servicios y/o prestaciones dinerarias. La LAPAD establece que los servicios garantizados por la AGE dependiendo del grado de dependencia (Anexo I) serán: los servicios de prevención de las situaciones de dependencia y los de promoción de la autonomía personal; teleasistencia; ayuda a domicilio; centros de día y de noche y atención residencial. Estos servicios se facilitarán a través de las Redes de Servicios Sociales de las distintas Comunidades Autónomas. Si no fuera posible la prestación de alguno de estos servicios, en los Convenios suscritos entre las CCAA y el Estado se incorporará la denominada prestación vinculada. Estos servicios deben ser preferibles antes que las prestaciones dinerarias también reguladas: Prestación económica vinculada al servicio; cuidados en el entorno familiar y apoyo a cuidadores no profesionales y de asistencia personal. Sin embargo en la práctica la predilección tiende hacia éstas últimas por la facilidad en su gestión (Rodríguez, 2009: 49).

Las Comunidades Autónomas tienen la potestad de regular el catálogo de servicios que se van a ofertar. Hasta el año 2011, en Castilla y León no existía una norma que lo regulara. Tras varias peticiones procedentes del procurador del común de este territorio (PCCyL, 2008: 9-10, 2010: 19), se aprobó la Orden Fam/763/2011, de 6 de junio por el que se aprueba el catálogo de prestaciones de dependencia de Castilla y León. Posteriormente la Orden Fam/644/2012, de 30 de julio adecúa la normativa a las nuevas condiciones que marca el RD Ley 20/2012 de 13 de julio de medidas para garantizar la estabilidad presupuestaria y de fomento de la competitividad, en la que se regulan las prestaciones que se ofertan, el cálculo de la capacidad económica y las medidas de apoyo a los cuidadores y que ya ha sufrido modificaciones a través de la Orden Fam/1133/2012, de 27 de diciembre.

La financiación de estas prestaciones es tripartita: AGE, CCAA y aportación del usuario. Las Comunidades Autónomas deberán regular las condiciones de acceso a las prestaciones, teniendo en cuenta lo que CTSAAD dispone en la Resolución de 2 de diciembre de 2008. En primer lugar, se debe determinar la capacidad económica del beneficiario, a través del cómputo de todos los elementos que componen su renta y su patrimonio. El punto de referencia de cómputo lo establece la declaración fiscal o pensión conocida a la fecha del hecho causante. La determinación de la capacidad económica será la resultante de la renta incrementada en un porcentaje de su patrimonio neto en función de la edad del beneficiario. En el caso de Castilla y León la edad del individuo no se considera. Se entiende en el grado de severidad por lo que inicialmente el efecto de la edad estaría recogido en la baremación practicada, aunque no necesariamente.

El beneficiario participará en la financiación de las prestaciones concedidas teniendo en cuenta su capacidad económica y la naturaleza de la prestación. En concreto, para el servicio de atención residencial, participarán en los costes de manutención y gastos hoteleros entre el 70 y 90 por ciento de su capacidad económica. En Castilla y León, tras la aprobación de la Orden Fam/1133/2012, de 27 de diciembre, por la que se modifica la Orden Fam/644/2012, de 30 de julio se establece que cuando la atención residencial sea compatible con la promoción

2 Una de las primeras Comunidades Autónomas que dispusieron normas acerca de cómo debe ser realizado el PIA fue la de Madrid (Orden 2386/2008, de 17 de diciembre). Sin embargo no es una Comunidad Autónoma que destaque por implantación de la Ley de Dependencia (AEDyGSS, 2013 (c): 1). El porcentaje de desatendidos en Castilla y León está muy por debajo del 10\%, mientras que la Comunidad de Madrid se eleva hasta el 20\%, si bien ambas se encuentran por debajo de la media española del 23\%, (AEDyGSS, 2013:64; 113 (a)). 
de la autonomía personal, la segunda prestación vinculada se destinará al servicio de menor coste aplicando las siguientes fórmulas:

* Para Grado III:

3,9 IPREM - R - PVS1

* Para Grado II:

3 IPREM - R - PVS1

* Para Grado I:

2,25 IPREM - R - PVS1

Donde PVS1 es la cuantía mensual de la primera prestación vinculada; R es la capacidad económica calculada según la normativa e IPREM es el indicador público de renta de efectos múltiples del año de referencia.

Los servicios que se regulan son los de prestación de servicio y de asistencia personal y cuidados en el entorno familiar. Para calcular las cuantías mensuales utilizan la formulación que viene reflejada en la Tabla 4 una vez aplicadas:

- La prestación vinculada al servicio o de asistencia personal será menor a la cuantía máxima establecida por Real Decreto para cada grado incrementado en un 20\%. En el caso de beneficiarios de Grado II la cuantía mensual se calcula de acuerdo a la siguiente expresión:

\section{2,065・IPREM - R $\leq$ Máximo • 1,75\%}

- La prestación de cuidados del entorno familiar será menor o igual a la cuantía máxima de referencia multiplicada por un coeficiente cuyo valor es 0,82352 .

En caso de que el beneficiario disfrute de otras prestaciones de análoga naturaleza como el complemento de gran invalidez que se deducirán lo calculado anteriormente.

En cuanto a las prestaciones económicas, si la capacidad económica del beneficiario es inferior al IPREM la prestación será el 100\% de las cuantías establecidas reglamentariamente para cada prestación. Aunque la Orden Fam 763/ 2011 lo contemplaba, sin embargo, la nueva redacción del 2012 lo suprime debido a que si no se contempla debería establecerse un coeficiente reductor que para Castilla y León sería:

$$
\%_{5}=100-20 \cdot \frac{\text { R-PNC }}{\text { IPREM }}
$$

en la que PNC= pensión no contributiva. Éste en ningún caso puede ser inferior al 40\% de la cuantía establecida para la Ayuda a Domicilio y la vinculada al servicio y el 75\% para los cuidados en el entorno familiar, salvo que se haya establecido algún tipo de incompatibilidad con los servicios del catálogo (según el criterio establecido en la resolución estatal).

A pesar de estas pautas el CTSAAD ha detectado que no hay homogeneidad en la determinación de la capacidad económica, y por ello establece una serie de criterios de mínimos que se deben cumplir. Las CCAA tienen la potestad de mejorar estos criterios. En la Resolución de 13 de julio de 2012, de la Secretaría de Estado de Servicios Sociales e Igualdad establece:

- La capacidad económica se determinará en atención a la renta y su patrimonio.

- Se considera renta los ingresos del beneficiario, derivados tanto del trabajo como del capital, así como cualesquiera otros sustitutivos de aquellos.

- Se considera patrimonio del beneficiario el conjunto de bienes y derechos de contenido económico de que sea titular, con deducción de las cargas y gravámenes que disminuyan su valor, así como de las deudas y obligaciones personales de las que deba responder.

- En todo caso, será de aplicación las deducciones relativas a prestaciones de análoga naturaleza y finalidad de los regímenes públicos de protección social. 
- El mínimo exento de participación económica de la persona beneficiaria, vendrá referenciado a la cuantía mensual del Indicador Público de Renta de Efectos Múltiples (IPREM), excluida la atención residencial.

En el año 2012 (Orden Fam/763/2011: 44827-44831) (Orden Fam/1133/2012: 80701-80702), establecen fórmulas para determinar la cuantía final de la prestación para Castilla y León y en principio se siguen las directrices expuestas anteriormente. Sin embargo lo que es llamativo es la adaptación que realiza sobre los cálculos de capacidad económica, en cuestión de un año, para adaptarse a las nuevas circunstancias que marcan los recortes establecidos por el RD-L 20/2012 de 13 de julio. Como resultado las cuantías mensuales se ven considerablemente reducidas e implica un incremento notable del esfuerzo económico que se le requiere a los dependientes en esta Comunidad Autónoma. En la tabla 4 se indica la comparativa de la formulación.

TABLA 4: Comparativa EN LOS CÁLCULOS DE LA CAPACIDAD ECONÓMICA

\begin{tabular}{|l|c|c|}
\hline \multicolumn{1}{|c|}{$\begin{array}{c}\text { Prestación } \\
\text { económica }\end{array}$} & $\begin{array}{c}\text { Orden Fam/1133/2012: Cálculo de la capaci- } \\
\text { dad económica vigente }\end{array}$ & $\begin{array}{c}\text { Orden Fam/763/2011: Cálculo de la capacidad } \\
\text { económica anterior }\end{array}$ \\
\hline $\begin{array}{l}\text { Vinculada al } \\
\text { servicio y de } \\
\text { asistencia } \\
\text { personal }\end{array}$ & $\mathrm{CM}=\mathrm{CR} \cdot\left[1,55-\left(0,55 \cdot \frac{\mathrm{R}}{\mathrm{IPREM}}\right)\right]$ & $\mathrm{CM}=\mathrm{CR} \cdot\left[1,1125-\left(0,15 \cdot \frac{\mathrm{R}}{\mathrm{IPREM}}\right)\right]$ \\
\hline $\begin{array}{l}\text { De cuidados } \\
\text { en el entorno } \\
\text { familiar }\end{array}$ & $\mathrm{CM}=\mathrm{CR} \cdot \mathrm{H} \cdot\left[2,3-\left(1,3 \cdot \frac{\mathrm{R}}{\mathrm{IPREM}}\right)\right]$ & $\mathrm{CM}=\mathrm{CR} \cdot\left[1,06-\left(0,08 \cdot \frac{\mathrm{R}}{\mathrm{IPREM}}\right)\right]$ \\
\hline
\end{tabular}

Fuente: Elaboración propia con la información extraída de la Orden Fam/1133/2012 y de la Orden Fam/763/2011.

CM: cuantía mensual.

CR: cuantía de referencia para cada prestación económica que coincide con las cuantías máximas establecidas por Real Decreto para cada grado de dependencia.

R: la capacidad económica personal calculada según la normativa.

IPREM: Cuantía mensual del Indicación Pública de Renta de Efectos Múltiples.

H: es un coeficiente corrector de la prestación cuyo valor es 0,82352

Caso I: Consideramos la prestación económica vinculada al servicio y como indicador de la capacidad económica personal la renta neta media mensual correspondiente a la Encuesta de Condiciones de Vida de 2011 (INE, 2011). En la Tabla 5 podemos observar además de estos datos, los relacionado con las cifras del IPREM mensual (IPREM, 2013) y las cuantías máximas garantizadas por el Estado para esta prestación para el Grado III (Anexo II , Tabla 9). Los resultados arrojan una conclusión inequívoca cual es el incremento en el esfuerzo de financiación del dependiente en una cuantía aproximada del $20 \%$.

TABLA 5: EJEMPLO dE CÁLCULO de CAPACIDAD ECONÓMICA CON R=RENTA NETA MENSUAL MEDIA PARA LA PRESTACIÓN VINCULADA AL $\operatorname{SERVICIO}(E N €)$

\begin{tabular}{|c|r|r|r|r|r|r|}
\hline Año & $\begin{array}{c}\text { Renta media } \\
\text { anual }\end{array}$ & IPREM & \multicolumn{1}{c|}{ CR } & $\begin{array}{c}\text { Capacidad económica } \\
\text { vigente }\end{array}$ & $\begin{array}{c}\text { Capacidad económica } \\
\text { anterior }\end{array}$ & \multicolumn{1}{c|}{ Diferencia } \\
\hline 2007 & 783,08 & 499,2 & 780,00 & 536,04 & 684,21 & $-21,66 \%$ \\
\hline 2008 & 817,17 & 516,9 & 811,98 & 552,56 & 710,78 & $-22,26 \%$ \\
\hline 2009 & 823,75 & 527,24 & 831,47 & 574,29 & 730,15 & $-21,35 \%$ \\
\hline 2010 & 796,92 & 532,51 & 833,96 & 606,21 & 740,57 & $-18,14 \%$ \\
\hline
\end{tabular}

Fuente: Elaboración propia utilizando datos del INE, 2011 y cuantías máximas de prestación vinculada al servicio Anexo II: Tabla 9.

Caso II: Prestación económica de cuidados en el entorno familiar bajo la misma base anterior.

En este caso (Tabla 6) las diferencias son más notorias alcanzando una variación de alrededor del 75\% de descenso. Ello implica un mayor esfuerzo económico para los dependientes en los que se haya establecido en su PIA que la atención debe prestarse en un entorno familiar. 
TABLA 6: EJEMPLO DE CÁLCULO DE CAPACIDAD ECONÓMICA CON R=RENTA NETA MENSUAL MEDIA PARA LA PRESTACIÓN ECONÓMICA DEL CUIDADOS EN EL ENTORNO FAMILIAR (EN $€$ )

\begin{tabular}{|c|r|r|r|r|r|r|}
\hline Año & $\begin{array}{c}\text { Renta media } \\
\text { anual }\end{array}$ & IPREM & \multicolumn{1}{c|}{ CR } & $\begin{array}{c}\text { Capacidad económica } \\
\text { vigente }\end{array}$ & $\begin{array}{c}\text { Capacidad económica } \\
\text { anterior }\end{array}$ & \multicolumn{1}{c|}{ Diferencia } \\
\hline 2007 & 783,08 & 499,2 & 487,00 & 104,56 & 455,10 & $-77,02$ \\
\hline 2008 & 817,17 & 516,9 & 506,96 & 102,22 & 473,26 & $-78,40$ \\
\hline 2009 & 823,75 & 527,24 & 519,13 & 114,96 & 485,39 & $-76,32$ \\
\hline 2010 & 796,92 & 532,51 & 520,69 & 152,01 & 489,59 & $-68,95$ \\
\hline
\end{tabular}

Fuente: Elaboración propia utilizando datos del INE, 2011 y cuantías máximas de prestación vinculada al servicio Anexo II: Tabla 9.

Es importante tener presente que las ayudas y prestaciones no son elegidas por el dependiente sino por la administración y únicamente se escucha el parecer del dependiente. Quien aprueba la prestación es el organismo público correspondiente.

La determinación de la capacidad económica se realiza con visos de fijar las ayudas económicas y no los servicios. Se tiene en cuenta cualquier fuente de ingresos tanto directa como indirecta, dando por hecho que el dependiente tiene capacidad suficiente para poder afrontar de manera eficiente la gestión de sus recursos. Sin embargo, una buena gestión del patrimonio inmobiliario del dependiente puede incrementar el flujo de renta directo que puede obtener llegado el caso de que lo necesitase. Esta es una gran oportunidad para ciertos sectores financieros de promocionar productos de licuación de patrimonio como pueden ser: hipoteca inversa; cesiones en alquiler de vivienda, etc. (Fernández y De la Peña, 2012: 498); servicios residenciales con mayores prestaciones que las que pueda ofrecer la garantía estatal (De la Peña, 2000 (b): 37-54), etc.

No obstante, antes de ofertar el producto financiero y/o actuarial para que cubra la situación de dependencia antes de que ocurra ésta, es imprescindible realizar un estudio de la limitación quizá más importante que impide esta oferta: la determinación fiable de una probabilidad de ocurrencia de la dependencia a cada edad.

\subsection{El baremo}

Para ofertar productos financieros y/o actuariales es necesario conocer con precisión aceptable las "bases técnicas" del propio producto. En este punto la ley da una información muy valiosa sobre estas cuestiones (Sánchez, 2009: 3-6). Lo relevante sería conocer la probabilidad de ocurrencia del suceso que se estudia: la dependencia.

La LAPAD nos da la clave para estudiar esta probabilidad: el baremo. Por otra parte, el Instituto Nacional de Estadística realiza una aproximación del número de personas que de forma subjetiva consideran que están en situación de dependencia a través de la Encuesta de Discapacidades, Autonomía personal y situaciones de Dependencia (EDAD 2008) (INE, 2010, (c)). Sin embargo ambos instrumentos no están bien enlazados. Al comparar el baremo y las variables que se consideran determinantes para la realización de las actividades básicas de la vida diaria se observa que no se dan muchas coincidencias. El baremo es demasiado preciso y la encuesta que realiza el INE se basa en la percepción subjetiva del usuario.

Hay que señalar que, desde que por primera vez apareció regulado el baremo con el Real Decreto 504/2007, de 20 de abril, ha sufrido modificaciones (ya contemplada en la LAPAD) Real Decreto 174/2011, de 11 de febrero, con entrada en vigor el 11/02/2012. Por lo tanto es lógico el desfase apuntado en EDAD 2008. Las principales diferencias entre el baremo y la encuesta se detallan en el Anexo III bajo la distribución de actividades básicas de la vida diaria: cuidados personales, mantenimiento de la salud, vestido y movimientos corporales y finalmente, actividades de desplazamiento y realización de tareas domésticas.

3 Resulta interesante observar cómo la primera de las actividades reguladas en las normas: "comer y beber", que se divide a su vez en varias tareas que se deben ejecutar, coincide textualmente con la primera variable a estudiar de la encuesta. Sin embargo, no está claro que la variable encuestada recoja toda la información de las tareas que especifica la legislación: Cortar y partir la comida en trozos; usar cubiertos para llevar la comida a la boca, etc.

Así mismo, se puede observar que en la primera regulación de la baremación se recogían las tareas relacionadas con la micción y defecación que se recogen también en la encuesta, sin embargo éstas desaparecen en la última versión del 2012. Por lo tanto, parece ser que la experiencia de la puesta en funcionamiento del sistema ha estimado que estas variables no deben ser determinantes a la hora de realizar el diagnóstico por dependencia. Por contraposición, se observa como algunas de las tareas que se evaluaban en la primera regulación, se desagregan en varias, en el nuevo baremo, como es el caso de "sentarse", que pasa a ser evaluada por: "Cambiar de tumbado a sentado en la cama"; "Permanecer sentado" y "Cambiar de estar de pie a sentado".

Finalmente, es importante señalar, que existen otras variables estudiadas en la EDAD 2008, que podrían encajar en algunas tareas descritas en las actividades que se señala en la regulación. Por ejemplo: "uso fino de las manos", podría encajar con: "abrochar botones o similar” o bien "Cortar y partir la comida en trozos". Podríamos incluirlas, pero corremos el riesgo de incluir información que no corresponda a la ejecución de las Actividades Básicas de la Vida Diaria (ABVD), saliéndonos por lo tanto de la definición que la LAPAD hace del estado de Dependencia (Ley 39/2006: 44144). 
EDAD 2008 no refleja con exactitud la imagen que, sobre la dependencia se desprende de la normativa. Se precisa por lo tanto que exista un mayor consenso entre las actividades y tareas reguladas con las encuestadas. La razón de ello estriba en que los datos de la encuesta se obtienen las tasas de prevalencia de dependencia. Si lo que se estudia y lo que se regula no coincide no se podrá realizar un estudio coherente para el cálculo de las probabilidades.

Por otra parte, se dejan de lado otras variables que quizá sean importantes a la hora de valorar un producto asegurador como, por ejemplo, el trabajo que se haya podido desempeñar en la vida laboral ya que ello puede afectar a la probabilidad de padecer algún síndrome geriátrico determinado (Caycedo, et al, 2011:147). Algunos estudios (Cambois y Robine, 2004:3); (Álvarez y Macías, 2009) ponen de relieve que dependiendo de qué labor se ha llevado a cabo en la vida activa se tiene mayor probabilidad de padecer restricciones en la realización de actividades de cuidado personal: bañarse, vestirse, alimentarse, usar el baño o tumbarse y levantarse de la cama.

Una vez evitados los inconvenientes relativos a la determinación de la prevalencia de ser dependientes se podrían obtener las probabilidades de dependencia aunque para ello se precisarían datos relativos a las probabilidades de fallecimiento para cada estado de severidad (Pitacco, 1995).

Salvadas estas limitaciones se podrían crear/ofertar activos financieros-actuariales adecuados para salvar las incompatibilidades que las propias comunidades autónomas puedan establecer. De entre los productos que se podrían potenciar gracias a estos cálculos estarían, entre otros: seguro de jubilación, seguro de rentas vitalicias, seguro de dependencia, planes de pensiones, hipoteca inversa, hipoteca mixta, cesión alquiler, etc. (Fernández y De la Peña, 2013); (Fernández y De la Peña, 2012:498).

\subsection{Las incompatibilidades en Castilla y León}

En la sección $5^{\text {a }}$ de la Orden Fam/763/2011 se regula el régimen de compatibilidad de las prestaciones de dependencia en Castilla y León. Para esta comunidad autónoma se establecen las siguientes incompatibilidades:

1) Las prestaciones económicas son incompatibles entre sí, aunque se establecen en casos puntuales, una serie de compatibilidades ${ }^{4}$, que deben ser tenidas en cuenta para la creación de productos tanto financieros como actuariales.

2) La prestación de servicios incluidos en el la LAPAD son incompatibles con las prestaciones económicas. Con la excepción de los servicios de Prevención y Teleasistencia.

3) Las prestaciones de servicios son incompatibles en sí, aunque existen también salvedades con carácter general, que conviene tener en cuenta a la hora de realizar productos para su cobertura y que puedan abaratar la prima de recibo5.

El régimen de compatibilidades e incompatibilidades anteriores se aplicará igualmente para la prestación económica vinculada a cada servicio. En este caso, también se especifican una serie de casos, siempre y cuando sean financiadas por un ente público y no por uno privado, o bien hayan sido calificadas como esenciales por la ley relativa a los servicios sociales de Castilla y León ${ }^{6}$.

4 La prestación económica de cuidados en el entorno familiar es compatible con la atención residencial temporal en un centro público o concertado por periodos de un máximo de 30 días al año, o en su caso con la ayuda económica para descanso de cuidador durante 15 días al año.

Cuando las actuaciones incluidas en el servicio de promoción de la autonomía personal no sean consideradas como esenciales por la Ley 16/2010, de 20 de diciembre de Servicios Sociales, podrá ser compatibles con la prestación económica de cuidados en el entorno familiar o en su caso con la prestación de asistencia personal.

5 El servicio de prevención es compatible con todos los servicios.

El servicio de promoción de la autonomía personal es compatible: con el servicio de centro de día y el residencial cuando el beneficiario tenga alguna deficiencia mental o discapacidad intelectual. En la modalidad de atención temprana con el servicio de ayuda a domicilio o en su caso con la prestación económica de cuidados en el entorno familiar, para los menores de 6 años con un grado III o II de severidad.

El servicio de atención residencial permanente en centros de personas con discapacidad es compatible con: Centro de día cuando la atención prestada por el servicio de atención residencial no sea completa.

La ayuda para descanso del cuidador es incompatible con: el disfrute de la estancia financiada públicamente, de la persona dependiente fuera del domicilio habitual por periodos iguales o superiores a 15 días en el año natural, ya sea por estancia residencial temporal, por asistencia a actividades de ocio o por cualquier causa para el descanso del cuidador.

Siempre y cuando los servicios que se mencionan a continuación no sean considerados como esenciales según la Ley 16/2010, de 20 de diciembre de Servicios Sociales, pero sean imprescindibles para poder acceder a los que realmente son considerados esenciales: La ayuda a domicilio: para poder acceder al servicio de promoción a la autonomía, centro de día y de noche, promoción de la autonomía personal en general y en su modalidad de atención temprana. Y La promoción de la autonomía personal para acceder: al servicio de ayuda a domicilio, servicio de centro de día y servicio de centro de noche. En el caso de personas con grado I de severidad cuando no alcancen la intensidad mínima prevista por la normativa vigente.

6 La ayuda a domicilio como esencial para acceder a las prestaciones de promoción de la autonomía personal en su modalidad de atención temprana y servicios de centro de día y de noche no es aplicable la compatibilidad a través de la prestación económica vinculada. 
Estas incompatibilidades pueden ser aprovechadas por las entidades privadas para poder satisfacer la potencial demanda de disfrutar de dos prestaciones económicas o la prestación de servicios que puedan resultar incompatibles, o combinaciones de ambas. Es más, existen individuos a los que se les había reconocido la ayuda domiciliaria con anterioridad a la ley a los que se les ha obligado a renunciar a la misma, para poderse beneficiar de la prestación económica de cuidados en el entorno familiar, (PCCyL, 2009:655). Este hecho afecta de modo especial a aquellos que, por rotar por las casas de los hijos, recalan en distintas comunidades autónomas, y cuando el turno les toca en Castilla y León han de suspender una de ellas por ser en este territorio incompatibles, aun teniendo el derecho de ambas reconocido en otra autonomía.

Además, a la luz de éstas, se pueden suplir carencias entre las prestaciones de servicios y económicas principalmente. Puede ocurrir que un dependiente mejore considerablemente su situación si pudiera disfrutar de la prestación económica para cuidados en el entorno familiar y hacer uso de un centro de día o residencial por periodos superiores a los que establece la ley, o incluso en instalaciones mejor preparadas y de carácter privado y no únicamente públicas o concertadas.

\section{COMENTARIOS Y CONCLUSIONES}

- La actual crisis que vive España está afectando en forma de recortes a la financiación del sistema de la seguridad social, aunque no es el único factor: el precio de los servicios y el aumento de la población objetivo agravan las dificultades para el sostenimiento del sistema. En el marco de la prestación por dependencia, el propio interesado ha visto como se incrementa la parte que debe financiar a su cargo para la misma cobertura.

- Lo anterior hace que cada vez exista un mayor riesgo de selección adversa: aquellos que más necesiten de cuidados más específicos, más probable es que no puedan acceder a prestaciones mejores y más adecuadas a su situación de dependencia, bien porque el Estado no se lo pueda proveer por coste, bien porque no tenga recursos suficientes para que se lo pueda sufragar el propio interesado.

- En el sistema de dependencia español las prestaciones han de ir en consonancia con el grado de dependencia que tenga el individuo y establecidas en su PIA. El afectado sólo será consultado y en ningún momento elegirá aquellas prestaciones que según su criterio le sean más beneficiosas. El complemento con productos aseguradores y financieros hace desaparecer esta limitación en cuanto a la capacidad de elección del beneficiario.

- Los productos que se podrían ofertar no sólo serían aquellos que suministren una corriente de dinero sino que se podrían contratar la prestación del servicio como los de alojamientos: viviendas, residencias, apartamentos, etc.

- Sin embargo, para que los productos financieros como Seguros de Dependencia, Planes de Pensiones, Hipotecas inversas, etc. se ofertan adecuadamente en el mercado es necesario tener una buena base técnica para estimar su coste con mayor fiabilidad y reduciendo los riesgos que asumen las entidades que los oferten. Por ello se precisa que se revisen y se sincronicen adecuadamente el instrumento de baremación que utiliza la administración atribuir la condición de dependiente, con la encuesta que realiza el INE para determinar la visión subjetiva de los individuos respecto de su capacidad de realizar determinadas actividades y tareas, además de profundizar en los estudios sobre la probabilidad de fallecimiento en cada estado de dependencia.

- Puede apreciarse que Castilla y León no ha trabajado para mejorar las prestaciones a sus dependientes sino únicamente las ha adaptado la normativa general. Las incompatibilidades son más exigentes. Ello no quiere decir que esta CCAA tenga una mala implantación de la Ley de Dependencia. De hecho el número de dependientes diagnosticados que no reciben prestación es uno de los más bajos, pero no ha realizado ninguna excepción a la norma general de incremento de los beneficios a los dependientes, con carácter general.

- El cuadro de incompatibilidades puede ser aprovechado por el sector privado para satisfacer la demanda de disfrutar de dos prestaciones económicas por ejemplo o prestación de servicios incompatibles. Incluso ello puede relajar las diferencias entre comunidades autónomas en cuanto a dependientes que deban cambiar de una a otra, cada poco tiempo.

- En esta Comunidad Autónoma existe un predominio de prestaciones económicas sobre los servicios ofertados debido principalmente a su bajo coste, gestión relativamente rápida y barata y una oferta insuficiente y cara de servicios. Por ello no cabe duda que puede ser un buen nicho para el mercado asegurador.

Tampoco será aplicable en el caso del servicio de promoción de la autonomía personal en el caso de ser financiadas de forma privada para los casos en los que esta atención no sea considerada esencial con la prestación económica de ayuda a domicilio o en su caso de prestación económica de asistencia personal y en el caso de personas en situación de grado I de severidad cuando no se alcance la intensidad mínima prevista, y con la ayuda a domicilio y centros de día y de noche. 


\section{BIBLIOGRAFÍA}

Abellán García, A. y Ayala García, A. (2012), "Un perfil de las personas mayores en España, 2012. Indicadores estadísticos básicos.” Informes Portal Mayores. Junio. № 131. Madrid. Disponible en: http://www.imsersomayores. csic.es/documentos/documentos/pm-indicadoresbasicos12.pdf (Consulta: 17/05/2013).

AdELANTADO, J. (2009), “Los servicios sociales y la cuarta pata (¿coja?) del Estado del Bienestar en España”, Revista Sociedade em Debate, 15, n. 1: 79-90. Disponible en: http://www.rle.ucpel.tche.br/index.php/rsd/article/ view/361/318 (Consulta: 25/05/2013).

Ahn, N. ; Alonso Meseguer, J.; Herce SAn Miguel, J. A. (2003), “Gasto Sanitario y envejecimiento de la población en España”, Documentos de trabajo, n 7. Bilbao: Fundación BBVA. http://www.fbbva.es/TLFU/dat/DT_2003_07.pdf (Consulta: 25/05/2013).

Alonso, P.; AlBARRÁN, I; FAJARDo, M. (2011), “Impacto territorial de la dependencia de España: población afectada y costes asociados a su atención”, Investigaciones regionales, №. 19: 5-24. Disponible en: http://www.aecr. org/images/ImatgesArticles/2011/5/01_GONZALEZ.pdf. (Consulta: 23/05/2013).

ÁlvAREZ, J. y MACíAS, J.F. (2009), Dependencia en geriatría. Salamanca: Universidad de Salamanca.

Arribas GonzÁlez de Durana, A.; Moreno Fuentes, F. J. (2009), “El tratamiento de la dependencia en los regímenes de bienestar europeos contemporáneos". Colección de estudios: Serie Dependencia. № 12007. Instituto de Mayores y Servicios Sociales (IMSERSO). Disponible en: http://www.imsersomayores.csic.es/documentos/documentos/arriba-tratamientodep-01.pdf (Consulta: 24/05/2013).

Asociación EstatAl de DiRECTORES Y GERENTES EN SERVICIOS SOCIALES (AEDyGSS) (2013):

- (a), X Dictamen del Observatorio. Anexo. Enero. Disponible en: http://www.directoressociales.com/images/ documentos/x\%20dictamenanexored.pdf (Consulta: 28/05/2013).

- (b), “La triste demagogia del Ministerio”. Artículo de opinión. Disponible en: http://www.directoressociales. com/prensa/168-la-triste-demagogia-del-ministerio.html (Consulta: 28/05/2013).

- (c), Escala: Tablas y Gráficos X Dictamen. Disponible en: http://www.directoressociales.com/images/Xescalabaja.pdf (Consulta: 29/05/2013).

AyUso GutiÉRREZ, M. y GUILlÉn EstANY, M. (2011), “El coste de los cuidados de larga duración en España bajo criterios actuariales: ¿es sostenible su financiación?”. El Estado de bienestar en la encrucijada: nuevos retos ante la crisis global. Ekonomi Gerizan. N 18 Federación de cajas de ahorros vasco-navarras. Disponible en: http://www. fcavn.es/Castellano/Publicaciones/Ekonomi_Gerizan/18 i.asp (Consulta: 19/5/2013).

BANCO DE ESPAÑA (2010), "Encuesta Financiera de las Familias (EFF) 2008: Métodos, Resultados y Cambios desde 2005." Boletín Económico, Diciembre 2010. Disponible en: http://www.bde.es/f/webbde/SES/estadis/eff/ eff2008_be1210.pdf. (Consulta: 21/05/013).

BARRIGA MARTín, L.A. (2012), "Presupuestos públicos y financiación de la atención a la dependencia - La cuadratura del círculo - Informe del Observatorio Estatal de la Dependencia Fecha de elaboración: 8 de junio. Asociación estatal de directoras y gerentes de servicios sociales. Observatorio estatal de la dependencia. Disponible en: http://www.directoressociales.com/images/ El\%20gasto\%20p\%C3\%BAblico\%20en\%20atenci\%C3\%B3n\%20a\%20la\%20dependencia\%20_an\%C3\%A1lisis_pdf (Consulta: 17/05/2013).

Barriga Martín, L.A.; Brezmes Nieto, M.J.; García Herrero, G.A.; Ramírez Navarro, J.M. (2013), Informe sobre el desarrollo y evaluación territorial de la ley de promoción de la autonomía personal y atención a las personas en situación de dependencia. X Dictamen de la dependencia. Enero. Observatorio estatal de la dependencia Disponible en: http://www.directoressociales.com/images/x\%20dictamen\%20.pdf (Consulta: 29/05/2013).

BLANCO, A.; URBANOS. R.; ThUISSARD, I.J. (2013), “Evolución de la prestación real media en España por edad y sexo (1998-2008) y su repercusión en las proyecciones de gasto sanitario público”. Gaceta Sanitaria. DOI: 10.1016/j. gaceta.2012.09.004.

\section{DE LA PEÑA EstebAN, J. I.(2000):}

- (a), Planes de previsión social. Madrid: Ediciones Pirámide (Grupo Anaya).

- (b), “Más allá del seguro de dependencia. El seguro de residencia”. Actualidad Financiera, Núm. 10, pp. 37-54.

CAycedo B, M. L., HeRRerA, S., Offir JimÉnez, K. (2011), “Descripción de los factores de riesgo para recaída en pacientes con diagnóstico de trastorno mental”. Revista Ciencias de la Salud [en línea], Nº (Sin mes). Disponible en: http://www.redalyc.org/articulo.oa?id=56222322004 (Consulta: 23/05/2013). 
CAMBOIS, E. y RoBinE, J.M., (2004), "Problèmes fonctionnels et incapacités chez les plus de 55 ans: des différences marquées selon les professions et le milieu social. Études et Résultats”, Direction de la Recherche des Études d'Évaluation et des Statistiques (DREES). Ministère des affaires sociales, du travail et de la solidarité. Ministère de la santé, de la famille et des personnes handicapées. Marzo n² 295. Disponible en: (Consulta: 23/05/2013).

CONDE-Ruiz, J. I. y Alonso, J. (2006), “El Sistema de Pensiones en España ante el reto del Envejecimiento”. Presupuesto y Gasto Público $n^{\circ} 44$. Instituto de Estudios Fiscales. Ministerio de Economía y Hacienda. Disponible en: http://www.ief.es/documentos/recursos/publicaciones/revistas/presu_gasto_publico/44_Pensiones.pdf (Consulta: 25/05/2013).

FERNÁNDEZ, M.C. y DE LA PEÑA, J.I.:

- (2012), “Cesión-alquiler de vivienda ante el coste por dependencia”. Anales de Economía Aplicada, XXVI. 498.

- (2013), “Probabilidades de dependencia en base a la encuesta de discapacidades 2008 del INE”. Anales de Economía Aplicada, XXVII. En imprenta.

Gómez García, J. M.; Peláez Fermoso, F. J.; García GonzÁlez, A.:

- (2007), “Los costes económicos de la evolución de la población anciana dependiente en Castilla y León”. XXI Reunión anual ASEPELT. Valladolid del 20 al 23 de junio. En línea: http://www.asepelt.org/ficheros/File/Anales/2007\%20-\%20Valladolid/A10_ECONOMIA\%20Y\%20DISCAPACIDAD.pdf (Consulta: 15/05/2013).

- (2011), “Dependencia, envejecimiento demográfico y economía social. Estimación de los potenciales efectos y valoración de la implantación del SAAD en Castilla y León”. CIRIEC-España, Revista de Economía Pública, Social y Cooperativa. En línea: http://www.redalyc.org/articulo.oa?id=17422036006 (Consultado: 15/05/2013).

Hidalgo -Vega, A.; Pérez - Camarero, S.; Llano, J.; PI - Corrales, G.; Fernández, A.; López - DíAz, J. y PéRez -VEiGA, J. P., (2010), "Estudio de las pautas previsibles de utilización futura de servicios sanitarios por mayores, frente a la viabilidad financiera del sistema de salud”. Disponible en: https://www.fundacionpfizer.org/publicaciones/estudio_pautas_previsibles_utilizacion_futura_servicios_sanitarios_mayores_frente_viabilidad_financiera_sistema_salud.html (Consulta: 25/05/2013).

INE:

- (2010), “Proyección de Población a Largo Plazo, 2009-2049”. http://www.ine.es/prensa/np587.pdf (Consulta: 12/11/2012).

- (2010), “Proyecciones a corto plazo de Población Residente a uno de enero: 2010 - 2020”. http://www.ine. es/metodologia/t20/t20269_m2010.pdf (Consulta: 12/11/2012).

- (2010), Encuesta sobre Discapacidad, Autonomía personal, y Situaciones de De-pendencia (EDAD). Disponible en: http:/l www.ine.es/jaxi/menu.do?type=pcaxis\&path=/t15/p418\&file=inebase\&L=0 (Consulta: 25/05/2013).

- (2011), Encuesta de condiciones de vida 2011. Resultados definitivos. http://www.ine.es/jaxi/tabla.do?path=/ t25/p453/a2011/lo/\&file=01001.px\&type=pcaxis\&L=0 (Consulta: 28/05/2013).

- (2012), “Estimaciones de la población actual de España” http://www.ine.es/jaxiBD/tabla.do?per=01\&type=db \&divi=EPOB\&idtab=4 (Consulta: 15/05/2013).

INDICADOR PÚBLICO DE RENTA DE EFECTOS MúltIPLES (IPREM), (2013), Disponible en: http://www.iprem.com.es/ (Consulta: 28/05/2013).

JUNTA DE CASTILLA Y LEÓN (2008), "Situación económica y social de las personas mayores. Año 2007". Consejería de Hacienda. Dirección General de Estadística. Disponible en: http://www.jcyl.es/web/jcyl/Estadistica/es/Plantilla100/1284159002098/_ _ _. (Consulta: 19/05/2013).

LA MONCLOA (2012), Documentos de Interés. Proyecto de Ley de Presupuestos Generales del Estado para el año 2013. Fecha de publicación: 29/09/2013. Disponible en: http://www.lamoncloa.gob.es/NR/rdonlyres/822443168CE9-45AF-AA91-CB9279559045/0/290912Presentaci\%C3\%B3nCongresoPGE2013.pdf. (Consulta 17/05/2013).

Maldonado Molina, J. A. (2002), Génesis y evolución de la protección social por vejez en España. Ministerio de Trabajo y Asuntos Sociales. Tesorería General de la Seguridad Social. Madrid.

MARTIN, L.G. (2011), Demography and aging, Handbook of Aging and de Social Sciences. Séptima edición. New York: 33-45.

Ministerio de HACIENDA Y AdMINISTRACIONES PúBliCAS (2012), Presupuestos Generales del Estado 2012. Informe Económico y Financiero. Disponible en: http://www.sepg.pap.minhap.gob.es/sitios/sepg/es-ES/Presupuestos/InformeEconomicoFinanciero/Documents/Informe\%20economico\%20financiero\%202012.pdf. (Consulta: 16/05/2013).

Muñoz Fernández, G. A. y SAntos RoldÁN, L. Ma (2012), “El Patrimonio Inmobiliario de los Mayores Como 
Complemento al Sistema de Pansiones (The Buildings of the Elderly As Supplemental Retirement Pensions)" Revista International Administración \& Finanzas, Vol. 5, No.1:17-32. Disponible en SSRN: http://ssrn.com/abstract=1952783 (Consulta: 25/05/2013).

NAREDO, J. M. y CARPINTERO, O. (2011), "Patrimonio inmobiliario y financiero de los hogares: tendencias y convergencia española con los estándares europeos", Papeles de la fundación de estudios financieros, cuaderno 39 : 99 - 115. Disponible en: http://www.fef.es/new/index.php?option=com_k2\&view=item\&task=download\&id=346_cb8 71fe238c71e3e3b54ea23cob5a191\&Itemid=145 (Consulta: 20/05/2013).

OCDE Social Expenditure Database (SOCX). Disponible en www.oecd.org/els/social/expenditure (Consulta: 25/05/2013).

Pérez de Orozco, A. y BAeza Gómez, P. (2006), "Sobre Dependencia y otros cuentos. Reflexiones en torno a la ley de promoción de la autonomía personal y atención a las personas en situación de dependencia”. Debate sobre la dependencia. Revista de relaciones laborales: Lan Harremanak, $N^{\circ} 15$. Servicio editorial de la Universidad del País Vasco. Disponible en: http:/l www.ehu.es/ojs/index.php/Lan_Harremanak/article/download/3114/2740 (Consulta: 20/05/2012).

PITACCO, E. (1995), Modelli attuariali per le assicurazioni sulla salute. EGEA.

POLO, C. y VIEJO, R. (2011), “Efectos de aumentar las pensiones no contributivas de jubilación y las pensiones con complemento a mínimo de jubilación y viudedad a las personas mayores en España”, Hacienda Pública Española / Revista de Economía Pública, 196-(1/2011): 79-106. Disponible en: http://www.ief.es/documentos/recursos/ publicaciones/revistas/hac_pub/196_4.pdf (Consulta: 27/05/2013).

Presupuestos Generales del Estado (PGE), (2013). Sección 60. Programa 231 I: Autonomía Personal y Atención a la Dependencia. Disponible en http://www.sepg.pap.minhap.gob.es/Presup/PGE2013Ley/MaestroDocumentos/PGE-ROM/doc/1/3/28/2/1/N_13_E_R_31_2_1_G_1_1_1231I_P.PDF (Consulta: 16/05/2013).

PROCURAdOR DEL COMúN DE CASTILLA Y LEÓN (PCCyL):

- (2008), “Aplicación de la Ley de Dependencia en Castilla y León”. Actuación de oficio: 20081109. Valladolid. Disponible en: https://www.procuradordelcomun.org/archivos/informesespeciales/1_1274873815.pdf (Consulta: 24/05/2013).

- (2009), “Familia, Igualdad de oportunidades y juventud”. Informe Anual. Área I. 651 a 666. Valladolid. Disponible en: https://www.procuradordelcomun.org/archivos/informesanualescapitulos/1_1274871741.pdf (Consulta: 24/05/2013).

- (2010), “Evolución de la aplicación en Castilla y León de la Ley 39/ 2006, de 14 de diciembre, de Promoción de la Autonomía Personal y Atención a las Personas en Situación de Dependencia”. Resolución. Expediente: 20100872. Valladolid. Disponible en: https://www.procuradordelcomun.org/archivos/informesespeciales/1_1291289245.pdf (Consulta: 26/05/2013).

PuGA, M. D.; SANCho, M.; TORTOSA, M. A.; MALMBerG, B. y SundStröm, G. (2011), “La diversificación y consolidación de los servicios sociales para las personas mayores en España y Suecia”, Revista Española de Salud Pública, vol. 85, núm. 6, noviembre-diciembre:525-539. Disponible en: http://www.scielosp.org/pdf/resp/v85n6/03_colaboracion_especial2.pdf (Consulta: 24/05/2013).

RodríGuez CABRERo, G, (2009), "El desarrollo de la política social de promoción de la autonomía y atención a las personas en situación de dependencia en España (2007-2009)”. Gestión y Análisis de Políticas Públicas. Nueva época $\mathrm{n}^{\circ}$ 2. Disponible en: http://revistasonline.inap.es/index.php?journal=GAPP\&page=issue\&op=view\&path\%5B \%5 $=28$ (Consulta: 29/05/2013).

SÁnchez Álvarez, I. L. A., S. y Quiroga García, R. (2007), "Diseño de hipotecas inversas en el mercado español." Instituto de mayores y servicios sociales. Disponible en: http://www.imsersomayores.csic.es/documentos/ documentos/imserso-estudiosidi-60.pdf (Consulta: 21/05/2013).

SÁNCHEZ DELGADO, E. (2009), Bases técnicas dinámicas del seguro de Dependencia en España: una aproximación en campo discreto, Madrid. Ed. Mapfre. Disponible en: http://www.fundacionmapfre.org/fundacion/es es/ images/bases-tecnicas-dinamicas-del-seguro-de-dependencia-en-espanya-una-aproximacion-en-campo-discreto-142.pdf (fecha de acceso: 24/05/2013).

Vaquerizo Collado, D.; Hennekam, H.; KNOP, R. y Ni Raghallaigh, E. (2011), “Informe: Situación de los Sistemas de Atención a la Dependencia en la Unión Europea”. Fundación Caser para la Dependencia. Octubre. Disponible en: http://www.fundacioncaser.es/actividad/situacin-de-los-sistemas-de-atencin-a-la-dependencia-en-la-unin-europea_2012102 (Consulta: 24/05/2013). 


\section{Legislación Estatal}

Ley 39/2006 de 14 de diciembre, de promoción de la Autonomía Personal y Atención a las personas en situación de Dependencia.

Real Decreto 504/2007, de 20 de abril por el que se establece el baremo de valoración de las situaciones de dependencia.

Real Decreto 614/2007, de 11 de mayo, sobre el nivel mínimo de protección del Sistema para la Autonomía y Atención a la Dependencia garantizado por la Administración General del Estado.

Real Decreto 727/2007, de 8 de junio, sobre criterios para determinar las intensidades de protección de los servicios y las cuantías de las prestaciones económicas de la Ley 39/2006, de 14 de diciembre, de Promoción de la Autonomía Personal y Atención a las personas en situación de Dependencia.

Real Decreto 6/2008, de 11 de enero, sobre determinación del nivel mínimo de protección garantizado a los beneficiarios del Sistema para la Autonomía y Atención a la Dependencia en el ejercicio 2008.

Real Decreto 7/2008, de 11 de enero, sobre las prestaciones económicas de la Ley 9/2006, de 14 de diciembre, de Promoción de la Autonomía Personal y Atención a las personas en situación de dependencia para el ejercicio 2008.

Real Decreto 179/2008, de 8 de febrero, por el que se modifica el Real Decreto 6/2008, de 11 de enero, sobre determinación del nivel mínimo de protección garantizado a los beneficiarios del Sistema para la Autonomía y Atención a la Dependencia en el ejercicio 2008.

Real Decreto 73/2009, de 30 de enero, sobre las prestaciones económicas de la Ley 39/2006, de 14 de diciembre, de promoción de la autonomía personal y atención a las personas en situación de dependencia para el ejercicio 2009.

Real Decreto 74/2009, de 30 de enero, por el que se determina el nivel mínimo de protección garantizado a los beneficiarios del sistema para la autonomía y atención a la dependencia para el ejercicio 2009.

Real Decreto 373/2010, de 26 de marzo, por el que se determina el nivel mínimo de protección garantizado a los beneficiarios del Sistema para la Autonomía y Atención a la Dependencia para el ejercicio 2010.

Real Decreto 374/2010, de 26 de marzo, sobre las prestaciones económicas de la Ley 39/2006, de 14 de diciembre, de Promoción de la Autonomía Personal y Atención a las personas en situación de dependencia para el ejercicio 2010.

Real Decreto 174/2011, de 11 de febrero, por el que se aprueba el baremo de valoración de la situación de dependencia establecido por la Ley 39/2006, de 14 de diciembre, de Promoción de la Autonomía Personal y Atención a las personas en situación de dependencia.

Real Decreto 175/2011, de 11 de febrero, por el que se modifica el Real Decreto 727/2007, de 8 de junio, sobre criterios para determinar las intensidades de protección de los servicios y la cuantía de las prestaciones económicas de la Ley 39/2006, de 14 de diciembre, de Promoción de la Autonomía Personal y Atención a las personas en situación de dependencia, y el Real Decreto 615/2007, de 11 de mayo, por el que se regula la Seguridad Social de los cuidadores de las personas en situación de dependencia.

Real Decreto 569/2011, de 20 de abril, por el que se determina el nivel mínimo de protección garantizado a las personas beneficiarias del Sistema para la Autonomía y Atención a la Dependencia para el ejercicio 2011.

Real Decreto-ley 20/2012, de 13 de julio, de medidas para garantizar la estabilidad presupuestaria y de fomento de la competitividad.

Resolución de 2 de diciembre de 2008, de la Secretaría de Estado de Política Social, Familias y Atención a la Dependencia y a la Discapacidad, por la que se publica el Acuerdo del Consejo Territorial del Sistema para la Autonomía y Atención a la Dependencia, sobre determinación de la capacidad económica del beneficiario y sobre los criterios de participación de éste en las prestaciones del Sistema para la Autonomía y Atención a la Dependencia.

Resolución de 4 de noviembre de 2010, de la Secretaría General de Política Social y Consumo, por la que se publica el Acuerdo sobre los criterios para determinar las intensidades de protección de los servicios y el importe de las prestaciones económicas para las personas reconocidas en situación de dependencia en grado I.

Resolución de 13 de julio de 2012, de la Secretaría de Estado de Servicios Sociales e Igualdad, por la que se publica el Acuerdo del Consejo Territorial del Sistema para la Autonomía y Atención a la Dependencia para la mejora del sistema para la autonomía y atención a la dependencia. 


\section{Legislación Autonómica}

Orden Fam/763/2011, de 6 de junio, por la que se regulan las prestaciones del Sistema para la Autonomía y Atención a la Dependencia en Castilla y León, el cálculo de la capacidad económica y las medidas de apoyo a las personas cuidadoras no profesionales.

Orden Fam/644/2012, de 30 de julio, por la que se regulan las prestaciones del Sistema para la Autonomía y Atención a la Dependencia en Castilla y León, el cálculo de la capacidad económica y las medidas de apoyo a las personas cuidadoras no profesionales.

Orden Fam/73/2012, de 15 de febrero, por la que se modifica la Orden FAM/824/2007, de 30 de abril, por la que se regula el procedimiento para el reconocimiento de la situación de dependencia y del derecho a las prestaciones del Sistema para la Autonomía y Atención a la Dependencia.

Orden Fam/1133/2012, de 27 de diciembre, por la que se modifica la Orden FAM/644/2012, de 30 de julio, por la que se regulan las prestaciones del Sistema para la Autonomía y Atención a la Dependencia en Castilla y León, el cálculo de la capacidad económica y las medidas de apoyo a las personas cuidadoras no profesionales.

Orden 2386/2008, de 17 de diciembre, por la que se regulan los procedimientos para el reconocimiento de la situación de dependencia, para la elaboración del programa individual de atención, las prestaciones económicas y servicios y el régimen de incompatibilidades.

Resolución de 29 de abril de 2010, de la Gerente de Servicios Sociales de Castilla y León, por la que se aprueba el modelo de solicitud para la valoración de la situación de dependencia y acceso a las prestaciones.

Resolución de 27 de julio de 2012, de la Gerencia de Servicios Sociales de Castilla y León, por la que se establece el coste máximo de plaza ocupada, relativo a la acción concertada en materia de reserva y ocupación de plazas en Centros de Servicios Sociales.

\section{ANEXO I}

PRESTACIONES QUE PROPORCIONA LA AGE

TABLA 7. SERVICIOS Y PRESTACIONES POR GRADO Y NIVEL DE DEPENDENCIA

\begin{tabular}{|c|c|c|}
\hline Grado y nivel de dependencia & Servicios & Prestaciones económicas \\
\hline Grado III y Nivel 1 y 2 & $\begin{array}{l}\text { Prevención y promoción de la autonomía } \\
\text { personal: } \\
\text { - Teleasistencia } \\
\text { - Ayuda a Domicilio } \\
\text { - Centro de Día } \\
\text { - Centro de Noche } \\
\text { - Atención Residencial }\end{array}$ & $\begin{array}{l}\text { Cuidados en el entorno familiar. } \\
\text {-Asistencia personal } \\
\text {-Prestación personal vinculada a servicio. }\end{array}$ \\
\hline Grado II y Nivel 1 y 2 & $\begin{array}{l}\text { Prevención y promoción de la autonomía } \\
\text { personal: } \\
\text { - Teleasistencia } \\
\text { - Ayuda a Domicilio } \\
\text { - Centro de Día } \\
\text { - Centro de Noche } \\
\text { - Atención Residencial }\end{array}$ & $\begin{array}{l}\text { Cuidados en el entorno familiar. } \\
\text {-Prestación personal vinculada a servicio. }\end{array}$ \\
\hline Grado I y Nivel 1 y 2 & $\begin{array}{l}\text { Promoción de la autonomía personal: } \\
\text { - Teleasistencia } \\
\text { - Ayuda a Domicilio } \\
\text { - Centro de Día } \\
\text { - Centro de Noche }\end{array}$ & $\begin{array}{l}\text { Cuidados en el entorno familiar. } \\
\text {-Prestación personal vinculada a servicio. }\end{array}$ \\
\hline
\end{tabular}

Fuente: Elaboración propia a partir de Real Decreto 727/2007, de 8 de junio. 
ANEXO II

INTENSIDADES DE LAS CUANTÍAS ECONÓMICAS GARANTIZADAS POR LA ADMINISTRACIÓN GENERAL DEL ESTADO

TABLA 8. CUANTÍA MÍNIMA DE PROTECCIÓN GARANTIZADA POR LA AGE

\begin{tabular}{|l|l|l|l|l|l|c|}
\hline \multicolumn{1}{|c|}{ Grado y nivel } & \multicolumn{1}{c|}{2007} & \multicolumn{1}{c|}{2008} & \multicolumn{1}{c|}{2009} & \multicolumn{1}{c|}{2010} & \multicolumn{1}{c|}{2011} & \multicolumn{1}{c|}{2012} \\
\hline Grado III y nivel 2 & $250,00 €$ & $258,75 €$ & $263,93 €$ & $266,57 €$ & $266,57 €$ & $231,28 €$ \\
\hline Grado III y nivel 1 & $170,00 €$ & $175,95 €$ & $179,47 €$ & $181,26 €$ & $181,26 €$ & $157,26 €$ \\
\hline Grado II y nivel 2 & - & $100,00 €$ & $102,00 €$ & $103,02 €$ & $103,02 €$ & $89,38 €$ \\
\hline Grado II y nivel 1 & - & - & $70,00 €$ & $70,70 €$ & $70,70 €$ & $61,34 €$ \\
\hline Grado I y nivel 2 & - & - & - & - & $60,00 €$ & $52,06 €$ \\
\hline
\end{tabular}

Fuente: Elaboración propia a partir de la información recabada en las siguientes normas: R D 614/2007, de 11 de mayo; RD 179/2008, de 8 de febrero; R. D. 74/2009, de 30 de enero; R. D. 373/2010, de 26 de marzo; RD 569/2011, de 20 de abril; RD-L 20/2012, de 13 de julio.

TABLA 9. CUANTíAS MÁXIMAS DE LAS PRESTACIONES ECONÓMICAS POR GRADO Y NiVEL PARA EL PERIODO 2007 - 2012 EN € MENSUALES

\begin{tabular}{|c|c|c|c|c|c|c|c|c|}
\hline \multirow{2}{*}{$\begin{array}{l}\text { Prestación } \\
\text { Económica }\end{array}$} & \multirow{2}{*}{\multicolumn{2}{|c|}{$\begin{array}{l}\text { Grado y Nivel } \\
2007\end{array}$}} & \multicolumn{6}{|c|}{ AÑOS } \\
\hline & & & \multirow{2}{*}{$\frac{2008}{780,00}$} & \multirow{2}{*}{\begin{tabular}{|l|}
2009 \\
811,98 \\
\end{tabular}} & \multirow{2}{*}{$\begin{array}{l}2010 \\
831,47 \\
\end{array}$} & \multirow{2}{*}{$\frac{2011}{833,96}$} & \multirow{2}{*}{$\begin{array}{l}2012 \\
833,96 \\
\end{array}$} & \multirow[b]{2}{*}{442,59} \\
\hline \multirow{6}{*}{ 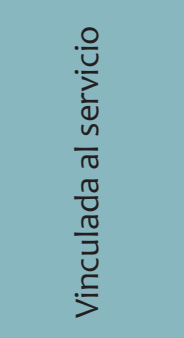 } & \multirow{2}{*}{ Grado III } & Nivel 2 & & & & & & \\
\hline & & Nivel 1 & 585,00 & 608,98 & 623,60 & 625,47 & 625,47 & 354,43 \\
\hline & \multirow{2}{*}{ Grado II } & Nivel 2 & -- & 450,00 & 460,80 & 462,18 & 462,18 & 286,66 \\
\hline & & Nivel 1 & --- & -- & 400,00 & 401,20 & 401,20 & 255,77 \\
\hline & \multirow{2}{*}{ Grado I } & Nivel 2 & --- & --- & --- & --- & 300,00 & 153,00 \\
\hline & & Nivel 1 & --- & --- & --- & --- & 225,00 & --- \\
\hline \multirow{6}{*}{ 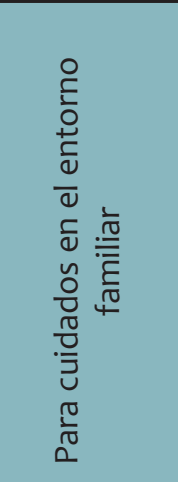 } & \multirow{2}{*}{ Grado III } & Nivel 2 & 487,00 & 506,96 & 519,13 & 520,69 & 520,69 & 520,69 \\
\hline & & Nivel 1 & 390,00 & 405,99 & 415,73 & 416,98 & 416,98 & 416,98 \\
\hline & \multirow{2}{*}{ Grado II } & Nivel 2 & --- & 328,36 & 336,24 & 337,25 & 337,25 & 337,25 \\
\hline & & Nivel 1 & --- & --- & 300,00 & 300,90 & 300,90 & 300,90 \\
\hline & \multirow[b]{2}{*}{ Grado I } & Nivel 2 & -- & --- & --- & -- & 180,00 & 180,00 \\
\hline & & Nivel 1 & --- & --- & --- & --- & 160,00 & 160,00 \\
\hline \multirow{6}{*}{ 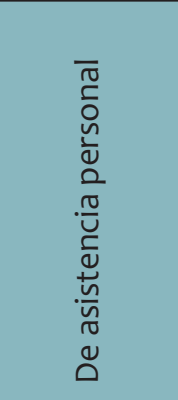 } & \multirow{2}{*}{ Grado III } & Nivel 2 & 780,00 & 911,98 & 831,47 & 833,96 & 833,96 & 833,96 \\
\hline & & Nivel 1 & 585,00 & 608,98 & 623,60 & 625,47 & 625,47 & 625,47 \\
\hline & \multirow{2}{*}{ Grado II } & Nivel 2 & --- & --- & --- & --- & --- & --- \\
\hline & & Nivel 1 & --- & --- & --- & -- & --- & --- \\
\hline & \multirow[b]{2}{*}{ Grado I } & Nivel 2 & --- & --- & --- & -- & --- & --- \\
\hline & & Nivel 1 & --- & -- & --- & --- & --- & --- \\
\hline
\end{tabular}

Fuente: Elaboración propia a partir de las siguientes normas: RD 727/2007, de 8 de junio; RD 7/ 2008, de 11 de enero; RD 73/2009, de 30 de enero; RD 374/ 2010, de 26 de marzo; Resolución 4 de noviembre de 2010; RD 175/2011, de 11 de febrero; RDL 20/ 2012 , de 13 de julio. 
TABLA 10. CuANTías MÁximas de LAS PRESTACIONES ECONÓMICAS POR GRADO Y NiVEL A PARTIR DE LA ENTRADA EN VIGOR DEL RD-L 20/ 2012 DE 13 DE JULIO EN ESPAÑA Y EN CASTILLA Y LEÓN

\begin{tabular}{|l|r|r|r|r|}
\hline GRADO & $\begin{array}{c}\text { Vinculada a Servicio y } \\
\text { asistencia personal }\end{array}$ & $\begin{array}{c}\text { Vinculada a Servicio } \\
\text { en Castilla y León }\end{array}$ & $\begin{array}{c}\text { Cuidados en } \\
\text { entorno familiar }\end{array}$ & $\begin{array}{c}\text { Cuidados en entorno } \\
\text { familiar en Castilla y } \\
\text { León }\end{array}$ \\
\hline Grado III & $715,07 €$ & $858,08 €$ & $387,64 €$ & $319,23 €$ \\
\hline Grado II & $426,12 €$ & $511,34 €$ & $268,79 €$ & $221,35 €$ \\
\hline Grado I & $300,00 €$ & $360 €$ & $153,00 €$ & $126 €$ \\
\hline
\end{tabular}

Fuente: Extraído del RD-L 20/ 2012 de 13 de julio, de medidas para garantizar la estabilidad presupuestaria y de fomento de la competitividad.

\section{ANEXO III}

TABLAS COMPARATIVAS ENTRE EL BAREMO DE LA NORMATIVA DE DEPENDENCIA Y LAS VARIABLES QUE ESTUDIA LA EDAD 2008

TABLA 11. COMPARATIVA DE LAS ACTIVIDADES DE CUIDADOS PERSONALES SUSCEPTIBLES DE BAREMACIÓN POR LA LAPAD Y SU RELACIÓN CON LAS VARIABLES ESTUDIADAS DE LA EDAD 2008

\begin{tabular}{|c|c|c|}
\hline RD 504/2007, de 20 de abril & RD 174/2011 de 11 de febrero & Encuesta EDAD 2008 \\
\hline $\begin{array}{c}\text { Aplicables a todas las situaciones de } \\
\text { dependencia }\end{array}$ & Aplicable en todos los casos & Para los hogares \\
\hline Comer y beber & Comer y beber & \\
\hline Emplear nutrición y /o hidratación artificial & -- & \multirow{8}{*}{ Comer y beber } \\
\hline Abrir botellas y latas & -- & \\
\hline Cortar y partir la carne en trozos & Cortar y partir la comida en trozos & \\
\hline Usar cubiertos para llevar la comida a la boca & Usar cubiertos para llevar la comida a la boca & \\
\hline Sujetar el recipiente de bebida & -- & \\
\hline Acercarse el recipiente de bebida a la boca & Acercarse el recipiente de bebida a la boca & \\
\hline \multirow[t]{2}{*}{ Sorber las bebidas } & -- & \\
\hline & $\begin{array}{c}\text { Reconocer y/o alcanzar los alimentos } \\
\text { servidos }\end{array}$ & \\
\hline Regulación micción/defecación & $\begin{array}{l}\text { Higiene personal relacionada con la } \\
\text { micción y defecación }\end{array}$ & \\
\hline Acudir a un lugar adecuado & Acudir a un lugar adecuado & \multirow{6}{*}{$\begin{array}{l}\text { Higiene personal relacionada con } \\
\text { la menstruación } \\
\text { Higiene personal relacionada con } \\
\text { la micción } \\
\text { Higiene personal relacionada con } \\
\text { la defecación }\end{array}$} \\
\hline Manipular la ropa & Manipular la ropa & \\
\hline Adoptar y abandonar la postura adecuada & Adoptar y abandonar la postura adecuada & \\
\hline Limpiarse & Limpiarse & \\
\hline Continencia micción & -- & \\
\hline Continencia defecación & -- & \\
\hline Lavarse & Lavarse & \\
\hline Lavarse las manos & Lavarse las manos & \multirow{6}{*}{ Lavarse } \\
\hline Lavarse la cara & & \\
\hline Lavarse la parte inferior del cuerpo & Lavarse la parte inferior del cuerpo & \\
\hline \multirow[t]{3}{*}{ Lavarse la parte superior del cuerpo } & Lavarse la parte superior del cuerpo & \\
\hline & Abrir y cerrar grifos & \\
\hline & Acceder a la bañera, ducha o similar & \\
\hline Otros cuidados personales & Realizar otros cuidados personales & \\
\hline Peinarse & Peinarse & \multirow{3}{*}{$\begin{array}{l}\text { Cuidados de las partes del } \\
\text { cuerpo }\end{array}$} \\
\hline Cortarse las uñas & Cortarse las uñas & \\
\hline Lavarse el pelo & Lavarse el pelo & \\
\hline
\end{tabular}

Fuente: Elaboración propia a partir de la información de RD Decreto 504/2007, de 20 de abril y R.D. 174/2011, de 11 de febrero y la metodología de la Encuesta de Discapacidad de 2008. 
TABLA 12. COMPARATIVA DE ACTIVIDADES DEL VESTIR, MANTENIMIENTO DE SALUD Y MOVIMIENTOS, SUSCEPTIBLES DE BAREMACIÓN POR LA LAPAD Y SU RELACIÓN CON LAS VARIABLES DE LA EDAD 2008

\begin{tabular}{|c|c|c|}
\hline RD 504/2007, de 20 de abril & RD 174/2011 de 11 de febrero & Encuesta EDAD 2008 \\
\hline Aplicables a todas las situaciones de dependencia & Aplicable en todos los casos & Para los hogares \\
\hline Vestirse & Vestirse & \\
\hline Calzarse & Calzarse & \multirow{5}{*}{ Vestirse y desvestirse } \\
\hline Abrocharse los botones & Abrocharse los botones o similar & \\
\hline Vestirse prendas de la parte inferior del cuerpo & Vestirse prendas de la parte inferior del cuerpo & \\
\hline \multirow[t]{2}{*}{ Vestirse prendas de la parte superior del cuerpo } & Vestirse prendas de la parte superior del cuerpo & \\
\hline & Reconocer y alcanzar la ropa y el calzado & \\
\hline Mantenimiento de la salud & Mantenimiento de la salud & \\
\hline Aplicarse medidas terapéuticas recomendadas & Aplicarse medidas terapéuticas recomendadas & \multirow{5}{*}{$\begin{array}{l}\text { Cuidado de la propia salud: } \\
\text { cumplir las prescripciones } \\
\text { médicas } \\
\text { Cuidado de la propia salud: } \\
\text { evitar situaciones de peligro }\end{array}$} \\
\hline Evitar riesgos dentro del domicilio & Evitar situaciones de riesgos dentro del domicilio & \\
\hline Evitar riesgos fuera del domicilio & Evitar situaciones de riesgos fuera del domicilio & \\
\hline \multirow[t]{2}{*}{ Pedir ayuda ante una urgencia } & Pedir ayuda ante una urgencia & \\
\hline & Solicitar asistencia terapéutica & \\
\hline Transferencias corporales & Cambiar y mantener la posición del cuerpo & \\
\hline \multirow{3}{*}{ Sentarse } & Cambiar de tumbado a sentado en la cama & \multirow{8}{*}{$\begin{array}{l}\text { Cambiar las posturas corpora- } \\
\text { les básicas. } \\
\text { Mantener la posición del } \\
\text { cuerpo }\end{array}$} \\
\hline & Permanecer sentado & \\
\hline & Cambiar de estar de pie a sentado & \\
\hline \multirow{2}{*}{ Ponerse de pié } & Cambiar de sentado en silla a de pie & \\
\hline & Permanecer de pie & \\
\hline Transferir mientras sentado & Transferir el propio cuerpo mientras sentado & \\
\hline Transferir mientras acostado & Transferir el propio cuerpo mientras acostado & \\
\hline Tumbarse & $\begin{array}{l}\text { Cambiar el centro de gravedad del cuerpo } \\
\text { mientras se está acostando }\end{array}$ & \\
\hline
\end{tabular}

Fuente: Elaboración propia a partir de la información de RD Decreto 504/2007, de 20 de abril y R.D. 174/2011, de 11 de febrero y la metodología de la Encuesta de Discapacidad de 2008.

TABLA 13. COMPARATIVA DE LAS ACTIVIDADES DE DESPLAZAMIENTO, SUSCEPTIBLES DE BAREMACIÓN POR LA LAPAD Y SU RELACIÓN CON LAS VARIABLES ESTUDIADAS DE LA EDAD 2008

\begin{tabular}{|c|c|c|}
\hline RD 504/2007, de 20 de abril & RD 174/2011 de 11 de febrero & Encuesta EDAD 2008 \\
\hline Aplicables a todas las situaciones de dependencia & Aplicable en todos los casos & Para los hogares \\
\hline Desplazarse dentro del hogar & Desplazarse dentro del hogar & \\
\hline \multirow{3}{*}{ Desplazamiento vinculado al autocuidado } & Realizar desplazamientos para vestirse & \multirow{7}{*}{$\begin{array}{c}\text { Desplazarse } \\
\text { dentro del hogar }\end{array}$} \\
\hline & Realizar desplazamiento para comer & \\
\hline & Realizar desplazamientos para lavarse & \\
\hline Desplazamientos no vinculados al autocuidado & Realizar desplazamientos no vinculados al autocuidado & \\
\hline $\begin{array}{l}\text { Accede a todos los elementos comunes de } \\
\text { las habitaciones }\end{array}$ & -- & \\
\hline-- & Realizar desplazamiento entre estancias no comunes & \\
\hline $\begin{array}{l}\text { Accede a todas las estancias comunes de la } \\
\text { vivienda en la que reside }\end{array}$ & Acceder a todas las estancias comunes del hogar & \\
\hline
\end{tabular}




\begin{tabular}{|c|c|c|}
\hline RD 504/2007, de 20 de abril & RD 174/2011 de 11 de febrero & Encuesta EDAD 2008 \\
\hline Aplicables a todas las situaciones de dependencia & Aplicable en todos los casos & Para los hogares \\
\hline Desplazarse fuera del hogar & Desplazarse fuera del hogar & \\
\hline Acceso al exterior & Acceder al exterior & \multirow{7}{*}{$\begin{array}{l}\text { Desplazarse fuera del } \\
\text { hogar }\end{array}$} \\
\hline Desplazamiento alrededor del edificio & Realizar desplazamientos alrededor del edificio & \\
\hline \multirow{2}{*}{ Desplazamiento cercano } & $\begin{array}{l}\text { Realizar desplazamientos cercanos en entornos co- } \\
\text { nocidos }\end{array}$ & \\
\hline & $\begin{array}{l}\text { Realizar desplazamientos cercanos en entornos } \\
\text { desconocidos }\end{array}$ & \\
\hline \multirow{2}{*}{ Desplazamiento Lejano } & $\begin{array}{l}\text { Realizar desplazamientos lejanos en entornos co- } \\
\text { nocidos }\end{array}$ & \\
\hline & $\begin{array}{l}\text { Realizar desplazamientos lejanos en entornos des- } \\
\text { conocidos }\end{array}$ & \\
\hline Utilización de medios de transporte & - & \\
\hline Realizar tareas domésticas & Realizar tareas domésticas & \\
\hline Preparar comidas & Preparar comidas & \multirow{4}{*}{$\begin{array}{l}\text { Preparar comidas } \\
\text { Adquisición de bienes y } \\
\text { servicios } \\
\text { Realizar los quehace- } \\
\text { res de la casa }\end{array}$} \\
\hline Hacer la compra & Hacer la compra & \\
\hline Limpiar y cuidar la vivienda & Limpiar y cuidar la vivienda & \\
\hline Lavar y cuidar la ropa & Lavar y cuidar la ropa & \\
\hline \multicolumn{3}{|c|}{$\begin{array}{l}\text { No se considerarán los casos específicos de personas que sufran incapacidades intelectuales. En general se tomarán las va- } \\
\text { riables de la Encuesta: Uso intencionado de los sentidos y Realizar taras sencillas como actividades generales que se pueden } \\
\text { enclavar en cualquiera de las categorías de actividades y tareas relacionadas en la tabla de baremación. }\end{array}$} \\
\hline
\end{tabular}

Fuente: Elaboración propia a partir de la información de RD Decreto 504/2007, de 20 de abril y R.D. 174/2011, de 11 de febrero y la metodología de la Encuesta de Discapacidad de 2008. 